
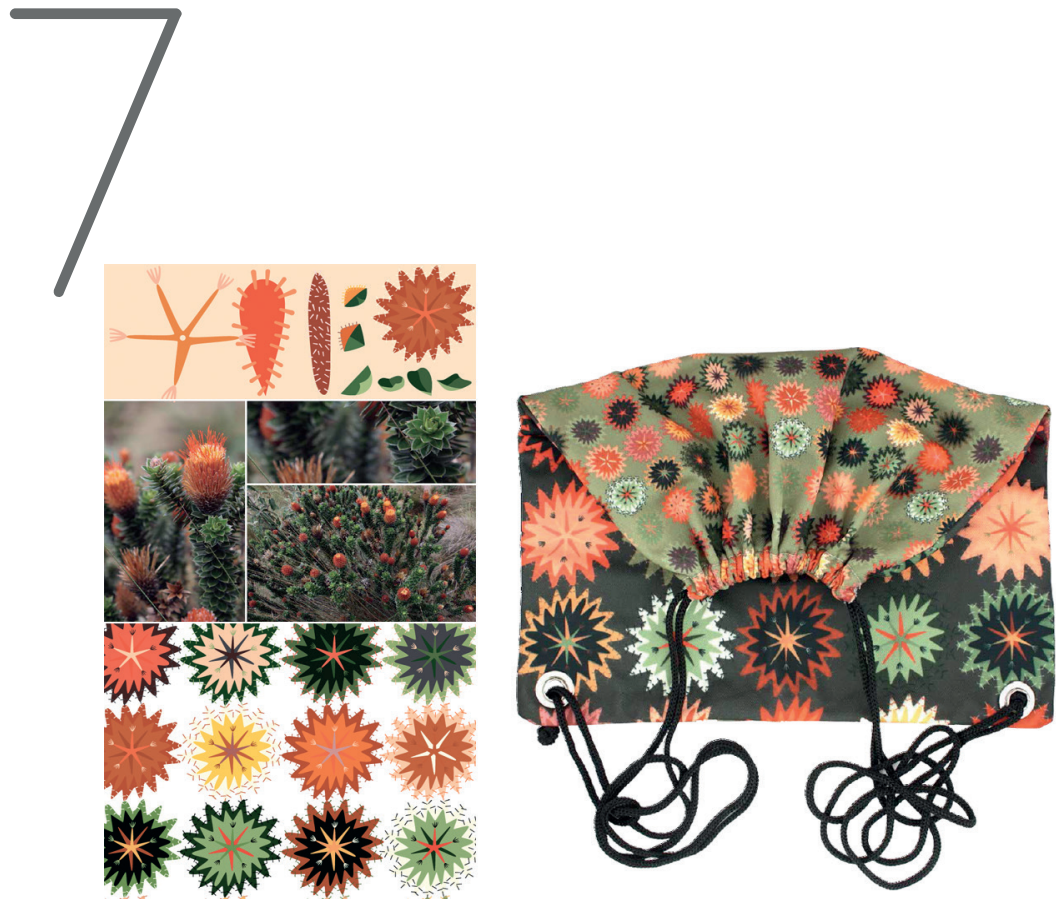

Síntesis gráfica de la chuquiragua del Parque Nacional Cajas aplicada en un objeto textil Gabriela Corral

\title{
DISEÑO GRÁFICO Y PATRIMONIO
}

\section{Lazo Galán, Juan Carlos}

Diseñador Investigador

Correspondencia: jlazo@uazuay.edu.ec 


\section{Resumen}

El diseño gráfico profesional en Ecuador se ha convertido en una carrera que tiene una enorme aceptación en el país con más de 24 universidades que tienen la carrera. Es una profesión que utiliza signos y símbolos arraigados en el inconsciente colectivo para generar comunicación. En un importante movimiento en los últimos años, los diseñadores gráficos han estado buscando referentes dentro del patrimonio ecuatoriano para generar propuestas con características propias, en algunos casos volviendo la mirada al pasado y en otras buscando en la cultura popular y en la naturaleza aquello que nos caracteriza. Este artículo analiza el diseño gráfico generado en los últimos 50 años y su relación con el patrimonio histórico, cultural y natural del país.

Palabras Clave: Cultura popular, precolombino, naturaleza, identidad, expresión visual

\section{GRAPHIC DESIGN AND CULTURE}

\section{Abstract}

Professional graphic design has become a career with a huge acceptance in Ecuador, with more than 24 universities offering it as a program of study. It's a profession that uses signs and symbols rooted in the collective subconscious to produce communication. In an important movement over the last few years, graphic designers have been searching for references within Ecuadorean culture to generate proposals with their own unique characteristics, in some cases, looking at the past and in others, searching within popular culture and in nature all that characterizes us. This article analyzes graphic design generated in the last 50 years and its relationship with the country's historical, cultural and natural heritage.

Keywords: Popular culture, pre-Columbian, nature, identity, visual expression. 


\section{Introducción}

Este artículo trata sobre el diseño gráfico profesional y su relación con el patrimonio ecuatoriano. Cuando hablamos de diseño gráfico profesional nos referimos a la propuesta hecha por profesionales para resolver problemas de comunicación visual.

La profesión del diseño gráfico está presente en el Ecuador desde fines de los años sesenta, realizada sobre todo por arquitectos y artistas visuales; pero se hace evidente desde los 80s, que es cuando los primeros profesionales graduados regresan con ese título desde universidades de fuera del país, y cuando los primeros egresados de las carreras de diseño de las universidades ecuatorianas empiezan a trabajar para agencias de publicidad o abren sus propios estudios de diseño.

El anhelo de encontrar nuevas formas de expresión que nos diferencien y nos revaloricen como pueblo se ha vuelto un motivo constante en el diseño gráfico ecuatoriano serio, que busca, a través de la investigación, hallar formas propias de expresión visual, y en esa búsqueda están lo precolombino, lo colonial y republicano, la naturaleza ecuatoriana y la cultura popular, es decir, aquello que está fuera de los círculos aceptados como académicos o de moda.

\section{Antecedentes}

El desarrollo gráfico ecuatoriano tiene un precedente extraordinario en la cerámica, en los sellos y en otras aplicaciones realizadas por los pueblos precolombinos que 
habitaron este territorio, culturas como Valdivia, Machalilla, Chorrera y las que vinieron luego. Esta influencia se extiende inclusive a la actualidad, sobre todo en los pueblos que han conservado más o menos intacta su cultura como lo son aquellos de la Amazonía ecuatoriana.

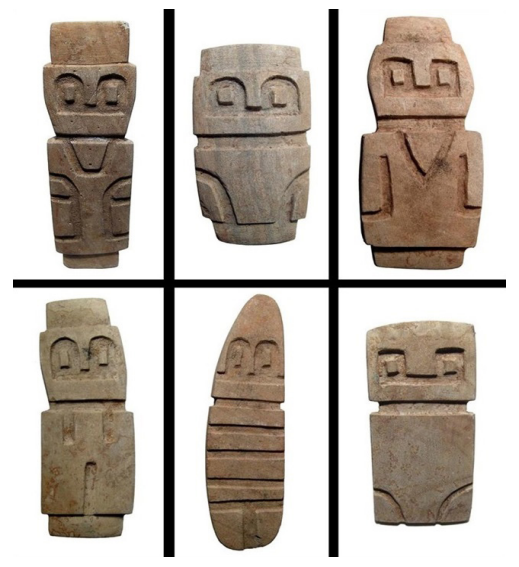

La cultura gráfica de estos pueblos tiene una calidad extraordinaria, durante miles de años se desarrolló una forma de pensamiento visual que se fue conformando y complejizando de tal manera que hoy son una parte importantísima de nuestro patrimonio visual, compartido con los países vecinos, con los cuales hubo un comercio constante y, por tanto, una influencia mutua evidente.

La llegada de los incas primero, y de los españoles después, destruyen la evolución gradual de esta labor gráfica compleja y rica, que va de un figurativismo exagerado a una síntesis abstracta orgánica o geométrica, y que es reemplazada por una forma de pensamiento abstracto y geométrico inca primero, y por el barroco recargado español a continuación. 
La conquista española convirtió a Latinoamérica en una parte de la civilización occidental. Durante más de 400 años el mestizaje degradó al arte indígena y a los restos de las culturas anteriores y las consideró inferiores. A pesar de eso, sin embargo, la mezcla de lo indígena y lo popular creó formas nuevas que pasaron a ser parte del arte popular, que igualmente eran observadas con cierto desprecio por las clases cultas y ricas que se referían al arte como a aquello que venía de España y del resto de Europa, o a aquellas tendencias artísticas que, si bien eran hechas en el Ecuador, emulaban lo sucedido en esos países.

La independencia no hizo más que cambiar los gustos de las elites ecuatorianas hacia lo afrancesado primero y luego hacia lo inglés, siguiendo las modas que el mundo seguía. Lo mestizo estaba ahí, pero, aunque habitaba los espacios de todas las clases sociales, seguía siendo visto como un complemento secundario del arte "culto", esto es evidente en las construcciones cuencanas de fines del siglo XIX y principios del siglo XX, en pleno auge de la cascarilla, donde aquellos que podían enviaban a sus hijos a estudiar en La Sorbona y de paso traían sus trajes o las planchas moldeadas y pintadas de Francia para decorar los cielos rasos y las paredes de sus casas, que han dado un carácter muy fuerte a la ciudad, mientras seguían utilizando la mano de obra local para fabricar mobiliario y menaje, en base a ese gusto importado.

No es sino hasta el año 1938 en que una señora húngara, que debido a la guerra había perdido dos colecciones consecutivas de arte popular, llega a Quito, huyendo de la persecución a los judíos en Europa. 
Venía con una mirada fresca y curiosa, gracias a sus estudios en arte ya había hecho ilustración para periódicos y libros europeos y diseñado cerámica para la fábrica Wierner Werkstatte, acostumbrada al arte europeo, no le sorprendió la forma de vida ni el arte "culto" de las clases altas ecuatorianas, al contrario, habiendo vivido en Marruecos, Brasil y Eritrea, le fascinaban las formas de la artesanía "primitiva". Como ella diría "siempre me gustó la gente primitiva, sencilla, eso que llaman el subdesarrollo".

Así es como Olga Fish inicia su colección en el Ecuador, buscando aquello que sus ojos veían como original y diferente, aquello que, para los ojos de las clases cultas de nuestro país de ese entonces, era pobre y desechable.

En una época en que a la artesanía se la compraba en los mercados o en los barrios populares, ella tuvo la visión de crear un almacén de folclore, donde compraba y vendía artesanías. Ahí fue donde también empezó a inspirarse en los motivos ecuatorianos para crear sus alfombras, algunas de las cuales, mejorando la técnica artesanal autóctona, fueron adquiridas por el MOMA y por la ONU en Nueva York, terminando por hacer una exposición en el Smithsonian Museum con su colección de artesanías autóctonas ecuatorianas.

A Olga Fish le debemos, en muchos sentidos, el aprecio que actualmente sentimos por nuestro patrimonio tangible e intangible. Sin afectar el espíritu del arte popular e indígena fue capaz de mejorar la calidad e incluso encontrar la manera de que ciertos tipos de artesanía, como los tejidos y los objetos en balsa, fueran aceptados en nuestros mercados e incluso se vendieran masivamente dentro y fuera del país. (Pérez Pimentel, n.d.) 
Este referente, que puede parecer alejado del diseño gráfico profesional, nos da una idea clara de en dónde inicia el cambio; de ese diseño que mira al exterior para reproducir o emular, a aquel que se mira a sí mismo para encontrar valor en la cultura y en las tradiciones propias.

\section{El patrimonio precolombino en manos profesionales}

Tuvo que ser otro extranjero el que, motivado por la expresión precolombina, haría el cambio en el diseño gráfico en el Ecuador. Huyendo del sistema comunista de Alemania Oriental Peter Mussfeldt llegó a Alemania Occidental en 1959, estudió arte en Dusseldorf, y luego de pasear por Europa, conocer a Picasso, Jean Cocteau y Lucien Clerque, llegó al Ecuador en 1962 invitado por un amigo, se enamoró del país y se quedó. (Gutiérrez, n.d.)

Peter Mussfeldt ha trabajado desde entonces en proyectos de diseño gráfico. Los diseños con un aire étnico los encontramos desde el año 1966 en el logotipo de la Sociedad Femenina de Cultura. (Moya Peralta, 1997)
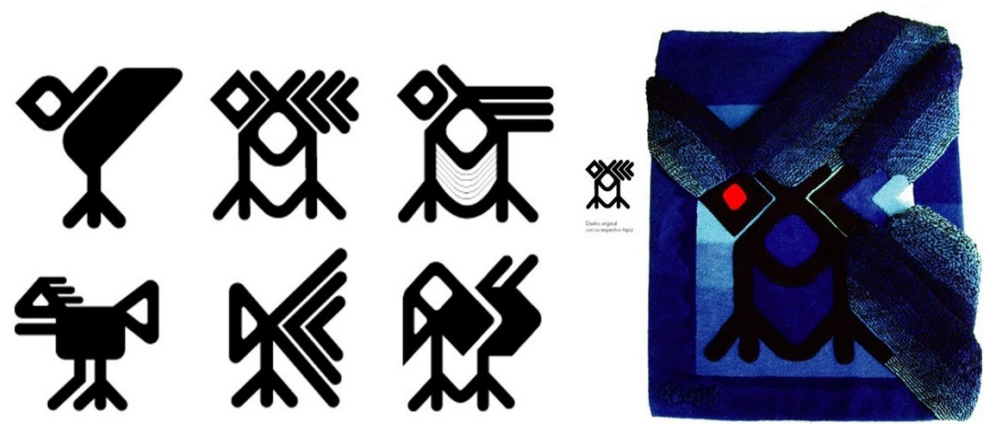
Mussfeldt recuerda que en 1975, luego de trabajar varios años en el país como publicista, un día se enfadó con los diseñadores y artesanos ecuatorianos que sólo reproducían el diseño y la cultura gráfica precolombina. Decidió darles una lección, así que tomó el concepto y diseñó una serie de pájaros, absolutamente contemporáneos, que remiten fuertemente a las formas encontradas en los sellos y la cerámica precolombina de la costa ecuatoriana. Estos diseños fueron aplicados por Mussfeldt sobre todo en alfombras. En el año 2010 la revista colombiana Proyecto Diseño mostró la producción de los "pájaros" a lo largo de toda la revista de su $30^{\circ}$ aniversario. (Salgado, 2010)
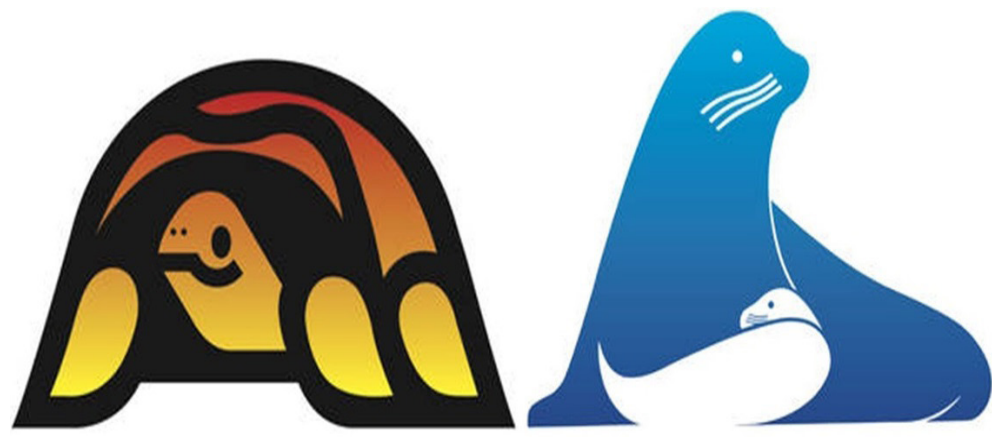

Por esa misma época decidió graficar motivos de las Islas Galápagos utilizando su concepto y modificando los colores originales de los animales. Creó una colección de T-Shirts. Sus tortugas rojas, piqueros verdes y lobos marinos azules se vendieron muchísimo, llegando a ser un souvenir muy común, que los extranjeros compraban junto con nuestros sombreros de paja toquilla. 


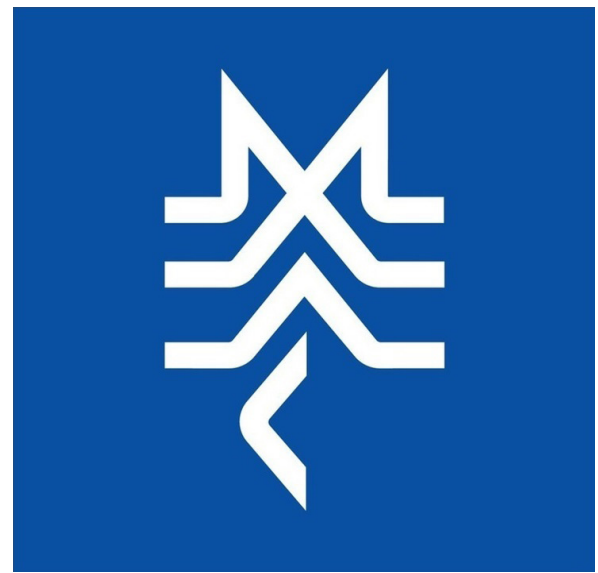

Conocido por su logo del Banco del Pacífico (1972) y por el logo del Banco Popular (1987), dos marcas que cambiaron la forma de ver a la identidad corporativa dentro del país, en el 2001 creó un logo muy emblemático en Guayaquil que es el del Museo Antropológico y de Arte Contemporáneo (MAAC), sus formas recuerdan a la vez lo precolombino y lo actual, por lo que se convierte en una marca muy sugerente y apropiada que reúne los dos extremos de la actividad del museo.
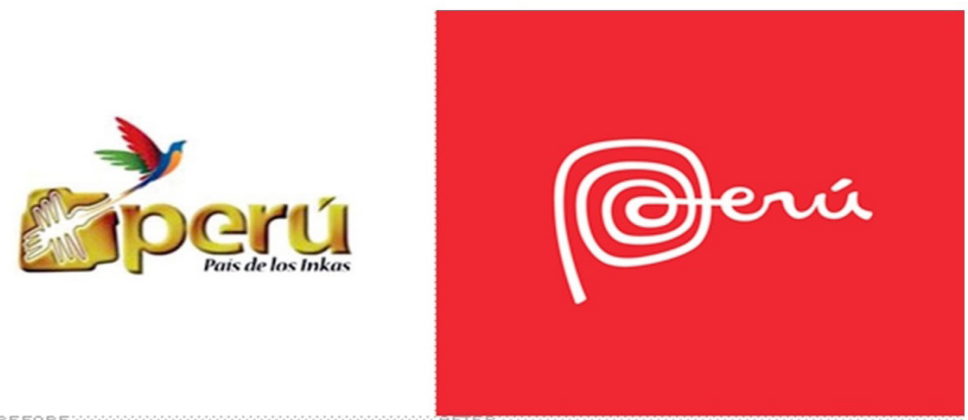
Durante muchos años Mussfeldt fue socio de Raúl Jaramillo, quien ganó un concurso para la marca país del Perú. Su marca recoge el patrimonio precolombino y lo mezcla con una visión más contemporánea creando una interesante sinergia que representó a Perú por casi una década, hasta que fue reemplazada por una marca que también acude a lo precolombino, pero que está realizada por la empresa argentina Futurebrand.
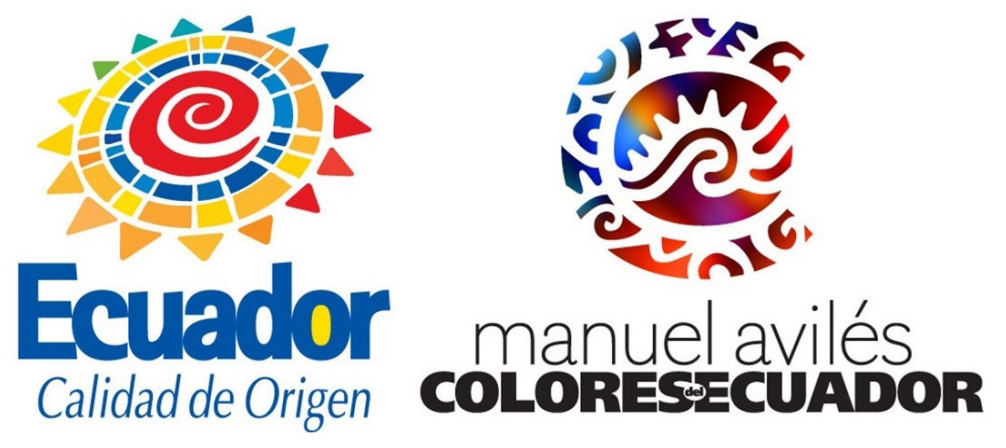

Jaramillo ha diseñado para instituciones ecuatorianas tomando también referencias precolombinas, es el caso de Ecuador Calidad de Origen y Colores del Ecuador.

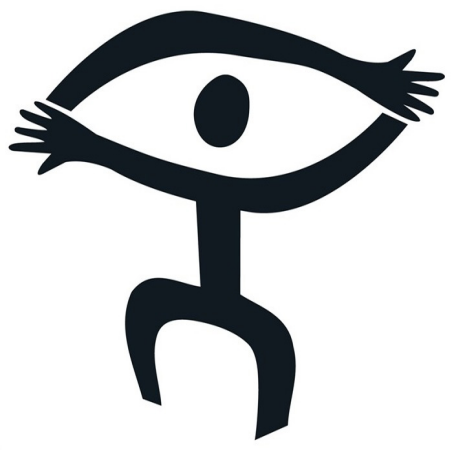


En la 3ra Bienal Diseño Gráfico Ecuador, en el 2000, este logo de Sandro y Silvio Giorgi, Arts-Américas, obtuvo el primer premio en la categoría Logos, con una propuesta que remite mucho a lo primitivo. En este caso ya no está presente una cultura determinada sino más bien semeja un petroglifo.
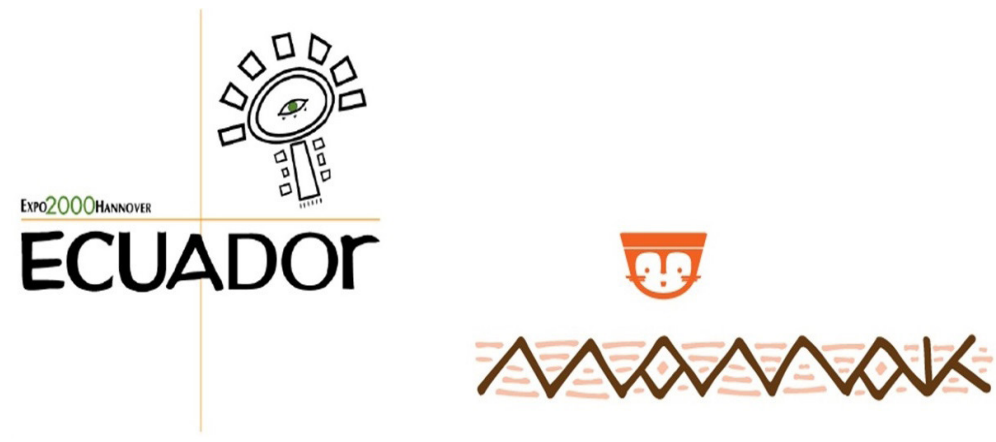

Expo2000Hannover fue la imagen del Ecuador en la Feria Mundial en Alemania. Fue diseñado por Yor Moscoso del estudio Ánima. Mámak, de Pablo Iturralde y Mayra Moncayo, también de Ánima, es una propuesta para galletas desarrollada en el 2013.

En el año 2012, Peter Mussfeldt y Esteban Salgado, representantes en el Ecuador de la Bienal Iberoamericana de Diseño, invitaron a Vanessa Zúñiga a presentar su trabajo en la III Bienal en Madrid. Para esto Vanessa diseñó una familia tipográfica a la que llamó "Sara/Maíz", inspirada en la imagen de un aríbalo del período de integración (500 $\mathrm{aC}-500 \mathrm{dC}$ ). El trabajo de Zúñiga ganó la Bienal. 


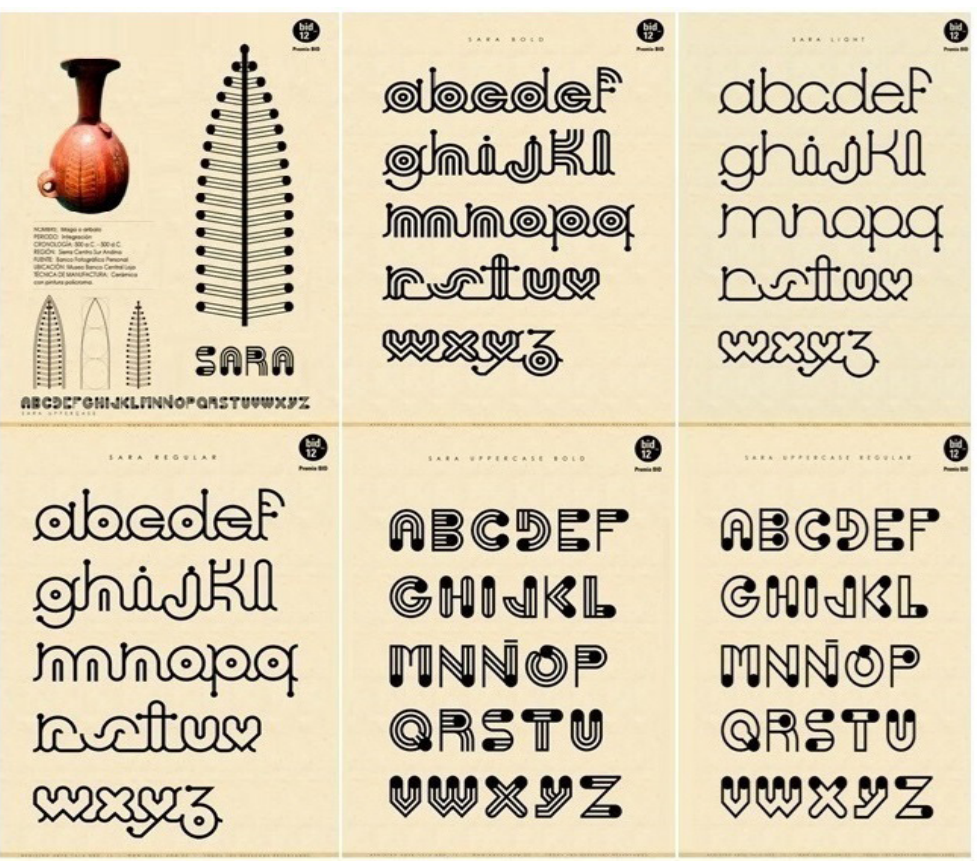

Vanessa Zúñiga, quien estudió diseño en la UDA, también fue seleccionada, junto con otros dos ecuatorianos, para la Bienal Tipos Latinos 2014 con la tipografía Sara/ Maíz aplicada en un proyecto llamado "Piensa, Imagina, Crea y Comunica", y también fue seleccionada con otra tipografía llamada Amaru Creador, que se inspira en la serpiente mitológica divina de un aríbalo de la cultura cañari - inca.

Todo el análisis para el encuentro de estas nuevas formas de expresión, basadas en un lenguaje precolombino, es el resultado de una tesis de maestría de Zúñiga, llamada "Aproximación a un Vocabulario Visual Básico Andino", los 

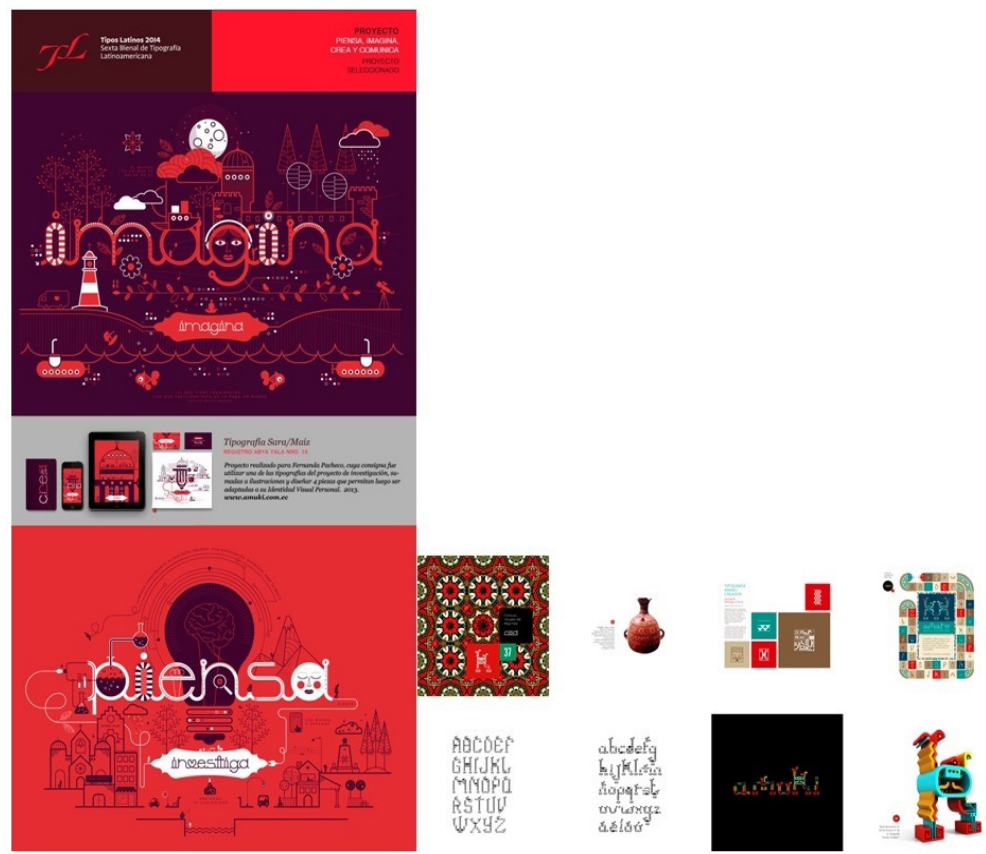

proyectos que se muestran aquí son de la segunda fase "Crónicas Visuales del Abya Yala",

"Crónicas Visuales de Abya Yala se enfoca en registrar los experimentos que se realizan con el repertorio de signos visuales de las culturas originarias del Ecuador... e intenta demostrar en cada registro que los signos visuales pueden ser apropiados y reutilizados con nuevos argumentos visuales, bajo un proceso de recontextualización que permita la revalorización de la memoria histórica del Ecuador, dejando de lado la actitud endormecedora y pasiva en donde los signos desterritorializados de otras culturas se imponen cada vez más en nuestro imaginario colectivo." (Zúñiga, 2014) 
Al momento (julio de 2014) ya hay 52 "registros" con 17 tipografías experimentales, 5000 "patterns" andinos y una gran colección de aplicaciones gráficas sobre muchos soportes bi y tridimensionales.
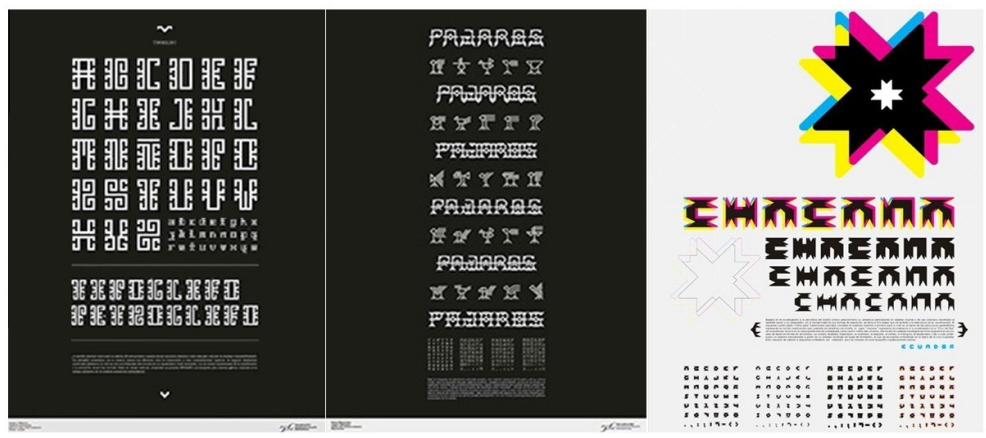

Es interesante observar que los otros dos seleccionados ecuatorianos para la Bienal Tipos Latinos 2014 parten también de la experimentación con formas precolombinas. Luis Bolaños con la tipografía Pájaros Andinos, inspirada en los pájaros de Mussfeldt, y César López con Tipoglifo, completan las cuatro obras seleccionadas para esta Bienal.

En el año 2010 el mismo Luis Bolaños fue seleccionado para la Bienal de ese año con la tipografía Chacana, inspirada en la cruz Inca.

En todas estas propuestas la inspiración es el pasado, pero la intención es la contemporaneidad. Las propuestas son novedosas pues no intentan ser una reproducción sino una interpretación actual de una cultura gráfica ya atemporal.

Esta tendencia a mirar hacia un pasado anterior a la conquista refleja una desesperada búsqueda del diseño 
gráfico ecuatoriano por encontrar una identidad difícil de describir. Si bien estamos muy alejados en el tiempo de aquellos rastros de una cultura con personalidad, como lo fueron los de las culturas que habitaron el Ecuador precolombino, estas formas quizá son lo único que puede ser distinto de aquello que nos caracteriza después de la conquista española, el arte barroco español, luego el neoclásico inglés y francés y por último el arte y la arquitectura modernas, que son una constante en toda Latinoamérica. La cultura indígena fue sofocada en sus rituales y su vestimenta, las técnicas constructivas fueron reemplazadas y el pensamiento previo a la conquista deformado hasta la casi extinción.

\section{La Colonia y la República como inspiración}

Si bien las formas coloniales están presentes en todo el país, es en Quito en donde en realidad se concentran con más densidad, y es ahí donde los diseñadores han hallado más inspiración para proponer formas actuales con aires coloniales.

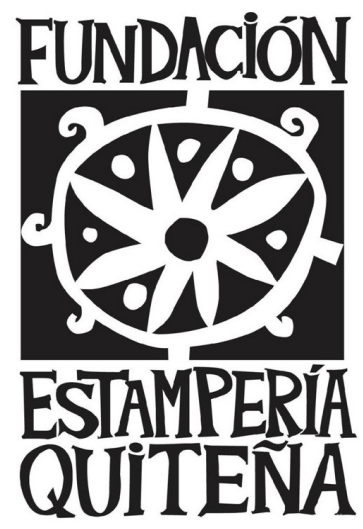


Estampería Quiteña es ganador de una mención en el 1er Concurso de Logos organizado por la Asociación de Diseñadores Gráficos en el 2000. Se aprecia claramente una combinación de diseño manual sobre un motivo barroco, la combinación crea una sensación de añoranza y modernidad muy marcadas, las autoras son Paula Barragán y Ana Fernández.
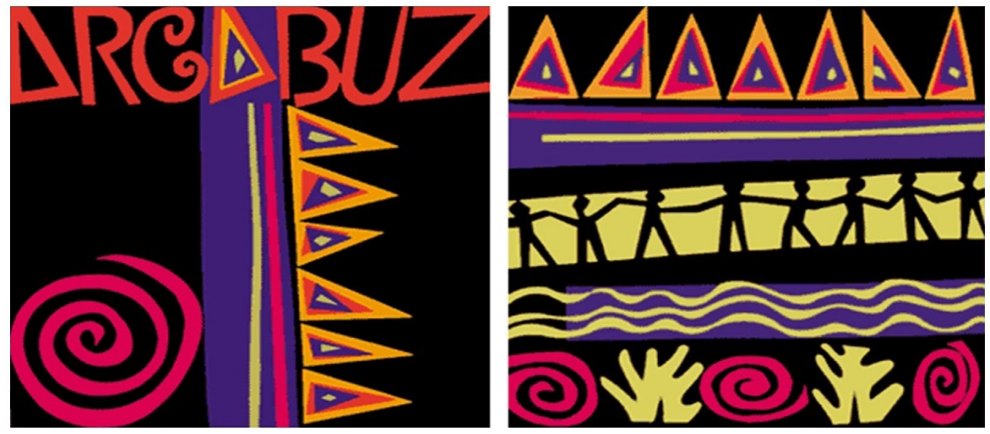

Este trabajo de Azuca Ingenio Gráfico del año 1988 es la portada del disco Arcabuz, de Hugo Idrovo y Héctor Napolitano. El disco canta el naufragio, a mediados del siglo XVI en las costas de Esmeraldas, del barco negrero, lo que permitiría el nacimiento de la cultura afroecuatoriana. La ilustración de las portadas del CD nos remiten a la cultura negra por sus contrastes, colorido y formas, si bien no necesariamente se ve "retro", como se le conoce al diseño que parece imitar formas del pasado.
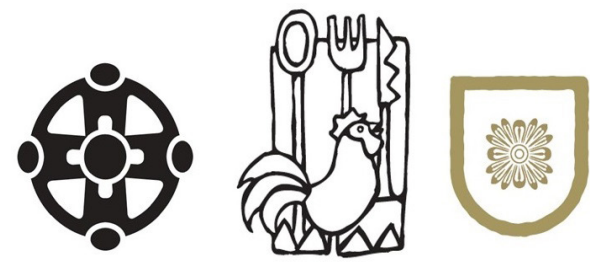

Casona de

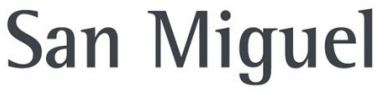


Ejemplos interesantes de recuperación del patrimonio colonial lo encontramos en el trabajo del estudio Ánima de Quito. El logo para la Secretaría Nacional de Educación y Cultura, y Cantagallo, ambos del año 1998, son diseños de Alberto Mont. La Casona es de Pablo Iturralde y Yor Moscoso en el 2010.

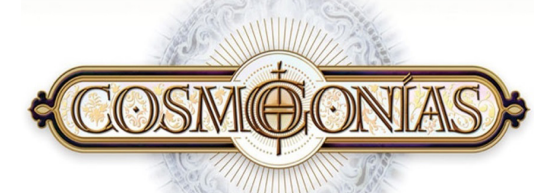

En este logo para Cosmogonías del Museo Nahim Isaías, el guayaquileño Raúl Jaramillo aprovecha las características barrocas para crear una composición compleja y rica en detalles.
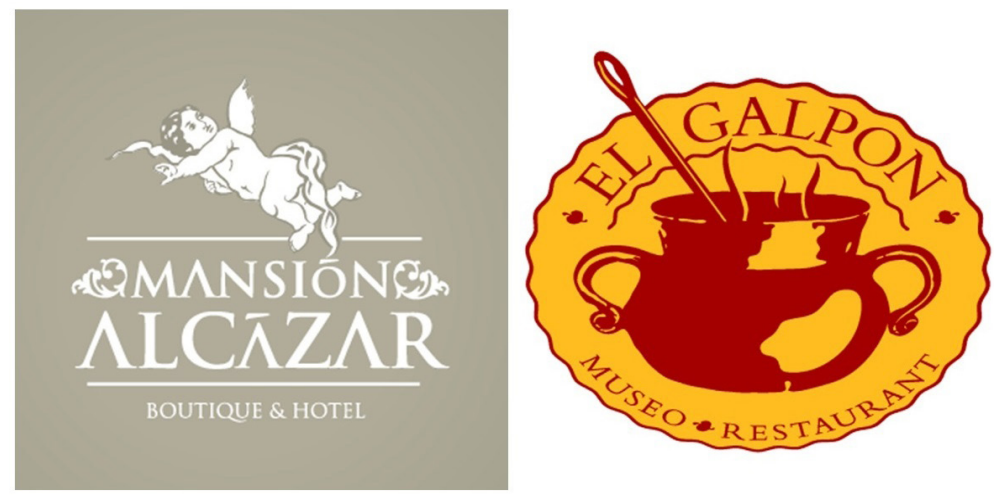
El uso de temáticas coloniales se da sobre todo en el turismo, en Cuenca, por ejemplo, varios de los hoteles del centro, ubicados en casas restauradas del siglo XIX y principios del XX utilizan el patrimonio colonial, como lo muestra este logo de Fabián Álvarez (2007). A la derecha, el logo del Museo Restaurant El Galpón, en Quito, es de Azuca Ingenio Gráfico.

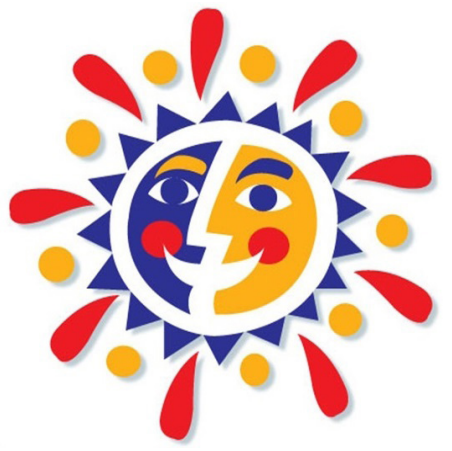

Las referencias al pasado pueden ser alegres y coloridas, como lo demuestra este logo de Peter Mussfeldt y Raúl Jaramillo, diseñado para la ropa de playa Mussfeldt Design, que se vende en Cancún México, desde 1994.
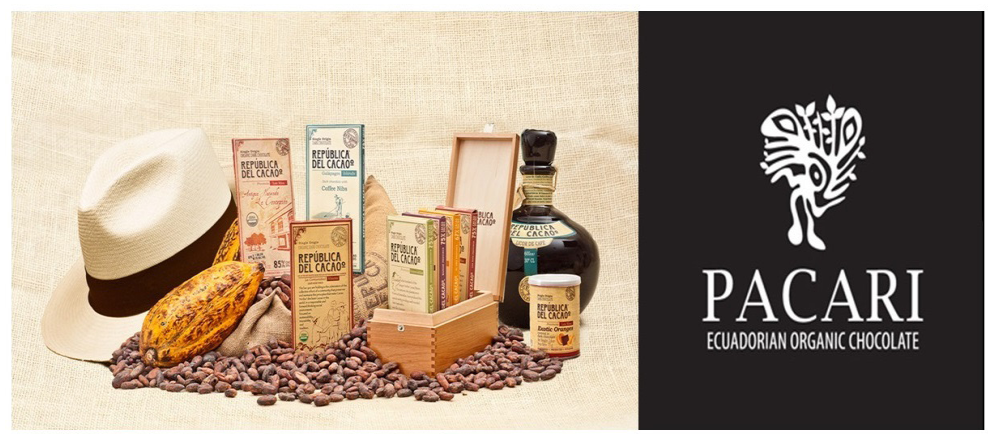
El chocolate ecuatoriano se ha convertido en el producto "gourmet" del país, marcas como Pacari y República del Cacao han conseguido premios internacionales a la calidad. En ambos casos los empaques intentan recurrir a una tradición visual que los relacione con la fabricación artesanal del pasado. El resultado es excelente. El logo y el embalaje de República del Cacao, que nos lleva a principios del siglo XX, es de Gustavo Miranda, y el logo de Pacari que retrata a un chamán en relación con la naturaleza es de Sebastián Malo y Paula Barragán.

\section{La naturaleza como inspiración}

La naturaleza ecuatoriana es rica y variada, es evidente entonces la inspiración que proviene de ella para quien tiene la sensibilidad de analizarla, sintetizarla, fusionarla.
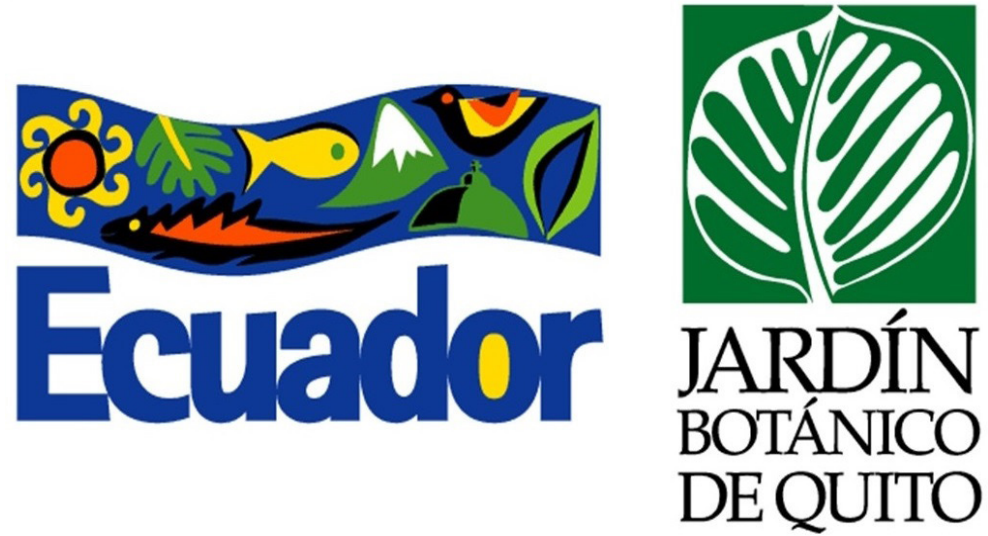

La marca Ecuador, de 1999, fue propuesta para el Ministerio de Turismo y se convirtió luego en la marca Ecuador durante la década del 2000. Pretende mostrar 
la diversidad y la alegría del país, en cambio en el logo del Jardín Botánico de Quito, 1989, el positivo y negativo de la imagen generan un movimiento y una sensación orgánica que se integran perfectamente dentro de la forma cuadrada en que está inserta. Ambos logos son de Paula Barragán para Azuca Ingenio Gráfico.
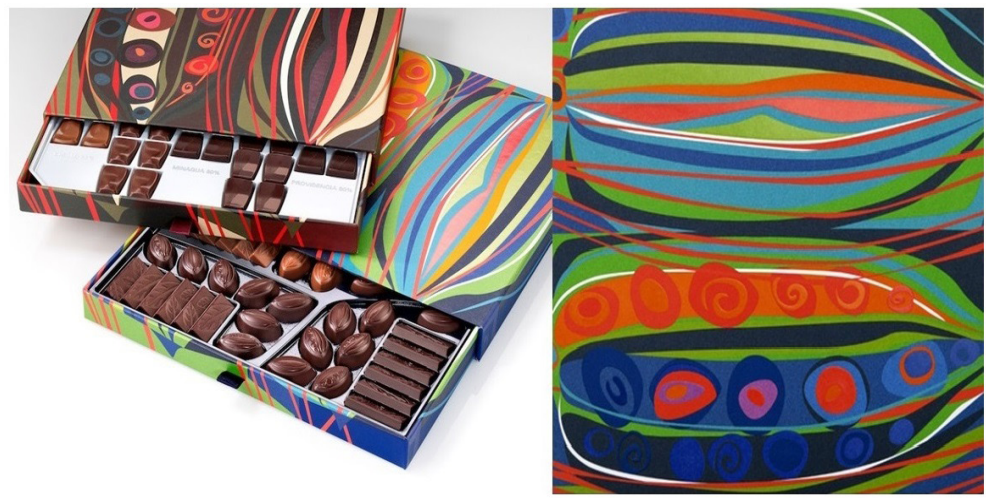

En esta propuesta más reciente, 2012, Paula Barragán diseñó las cajas y las formas de los chocolates para la Nestlé Suiza, un obsequio navideño de esta empresa que se distribuyó por todo el mundo. La influencia de este organicismo que está presente en la mayoría de las propuestas gráficas de Barragán, proviene de su obra en grabado. Ella reconoce que en algún momento dejó de separar el arte del diseño y ahora funde los dos sin problema.

El trabajo más reconocido que tiene el diseño ecuatoriano es el libro Pachanga, un documento hecho por Belén Mena que se publicó en Alemania y ganó el IF Gold Award 2008. Llegó a estar entre los mejores 10 libros publicados en el mundo en ese año. 

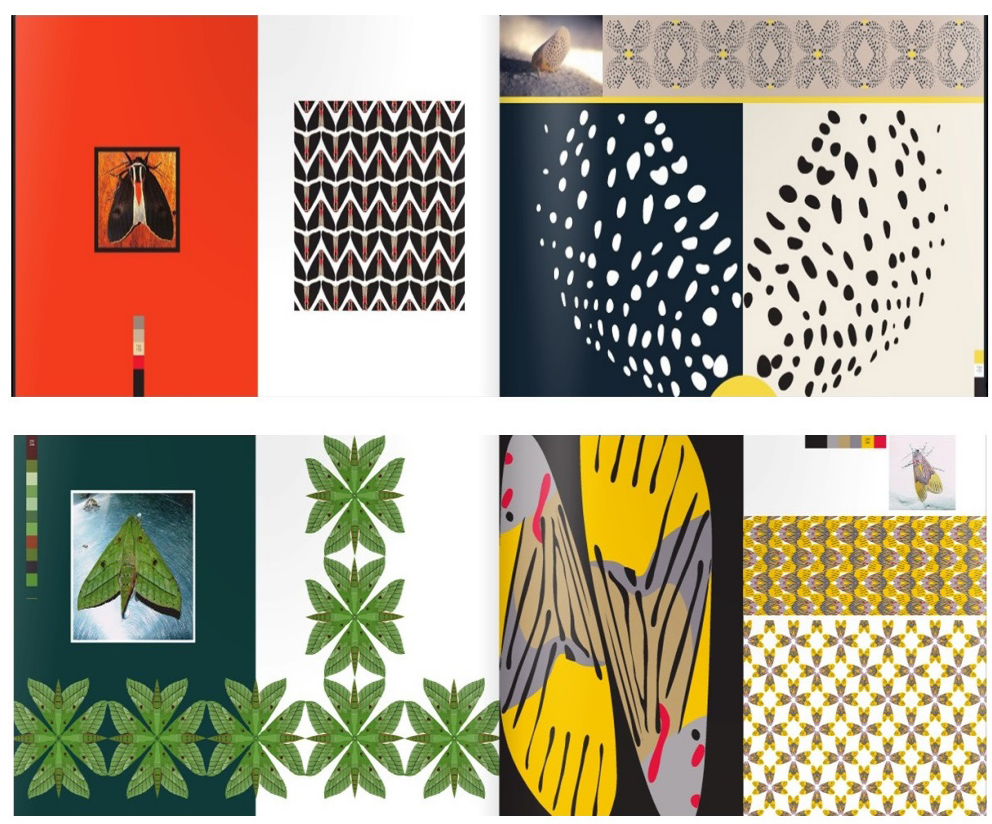

El concepto detrás de Pachanga es muy simple, Mena fotografió durante varios años a las mariposas nocturnas que llegaban a su casa en Mindo, y se dio cuenta del enorme potencial que había al descubrir sus texturas y morfologías, utilizando procesos básicos de diseño generó patrones y formas que se ven a lo largo de las 100 páginas del libro, un documento extraordinario que ha influido en el diseño ecuatoriano poderosamente.

"Pachanga es una investigación de diseño basada en el maravilloso mundo oculto de las polillas. Busca ser un proyecto que explora este recurso natural como base para analizar de forma bidimensional las posibilidades compositivas, geométricas, y cromáticas de este macro mundo y pretende hacer una analogía de la vida urbana de estos seres invisibles que salen 
por la noche de 'Pachanga', a lucir sus más exóticos trajes, como damas de la oscuridad." (Mena, 2014)

\section{Diseño y cultura popular}

El Diccionario de la Real Academia de la Lengua en su edición de 2001, define a Cultura como: «Conjunto de modos de vida y costumbres, conocimientos y grado de desarrollo artístico, científico, industrial, en una época o grupo determinado» y precisa a la Cultura Popular como «Conjunto de manifestaciones en que se expresa la vida tradicional de un pueblo».

Para Amadou Mahtar M'Bow, antropólogo senegalés que fue director de la UNESCO durante veinte años:

«Cultura es a la vez aquello que una comunidad ha creado y lo que ha llegado a ser gracias a esa creación; lo que ha producido en todos los dominios donde ejerce su creatividad y el conjunto de rasgos espirituales y materiales que, a lo largo de ese proceso, han llegado a modelar su identidad y a distinguirla de otras.» (Citado por Malo González, 2002)

Por tanto, la inspiración por parte de los diseñadores gráficos en la cultura popular vendría de tomar como referentes elementos de la tradición o de los rasgos espirituales o materiales que han conformado el carácter del Ecuador y del ecuatoriano, y que nos distingue de otras culturas.

Una tarea difícil por nuestra semejanza cultural con nuestros vecinos sobre todo, y en general con el resto de pueblos latinoamericanos; sin embargo se ha intentado, e 
incluso se ha conseguido que, a través del diseño gráfico, se generen referentes que enriquecen a esa cultura popular.

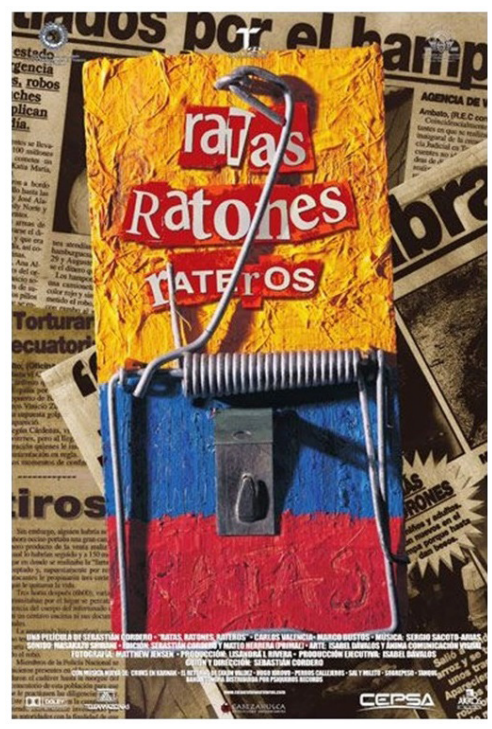

El cartel de Pablo Iturralde para la película más icónica del cine ecuatoriano: Ratas, Ratones, Rateros, de Sebastián Cordero 1998, se ha convertido en parte del imaginario visual colectivo ecuatoriano. Para conseguir el ambiente de la película utiliza elementos sumamente kitsch: la bandera del Ecuador y el diario El Extra como fondo. El cartel ha ganado premios en el país y se ha incluido en catálogos y exposiciones en varios países del mundo.

Marcas como Pilsener o la camiseta de la selección son parte también de ese patrimonio visual ecuatoriano. 

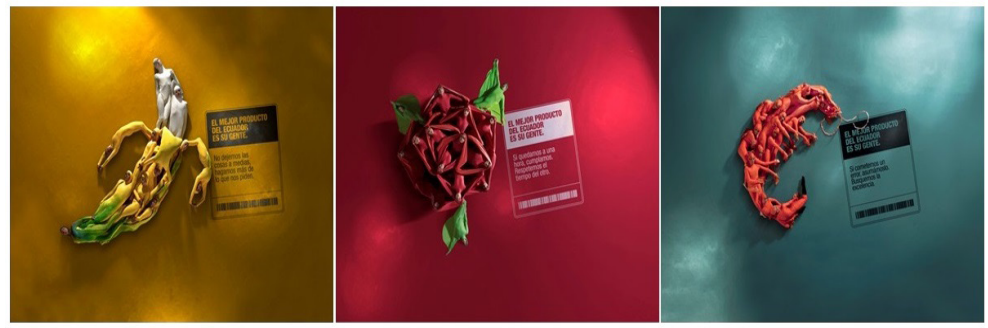

En el 2012 el Ministerio Coordinador de Conocimiento y Talento Humano contrató a la agencia La Facultad para crear una campaña en donde los protagonistas fueran los ecuatorianos. Con mucha sensibilidad artística la campaña es resuelta utilizando bailarines que forman visualmente nuestros productos de exportación, y dando a entender que lo que mejor que hace el país es ecuatorianos.

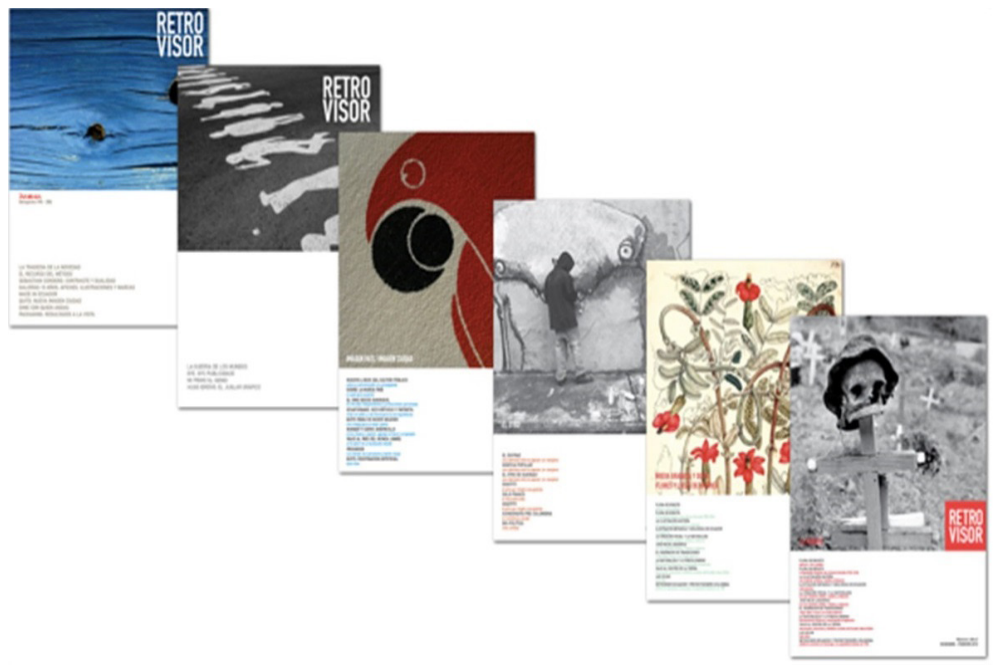


En una propuesta muy innovadora, el año 2008 el estudio Ánima, con Pablo Iturralde a la cabeza, inicia una publicación que está por ahora en el número 6 , de una revista que recoge los "estilos" contribuyentes a la identidad visual del país. En sus páginas se ha analizado la identidad, las marcas país, la expresión gráfica popular, el patrimonio, el grafiti, etc. La publicación ha ganado el Premio Especial del Jurado en la II Bienal Iberoamericana de Diseño en Madrid 2010 y desde el tercer número fue financiada por el Ministerio de Cultura.

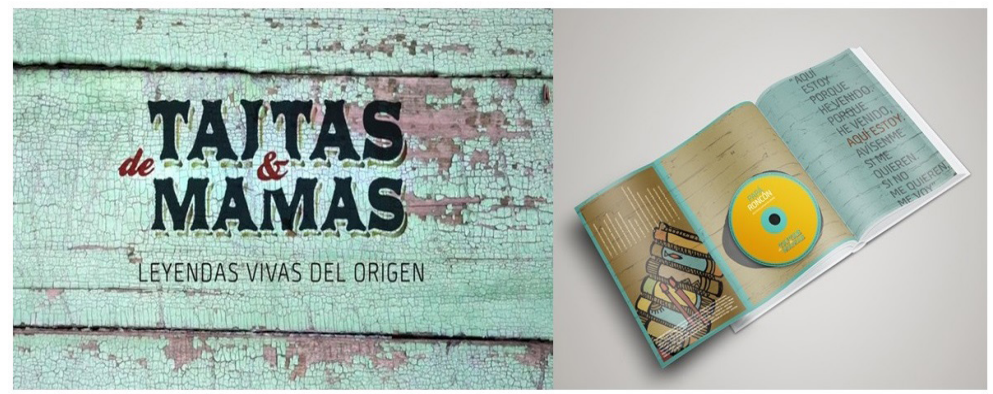

En el 2013 el trabajo de Belén Mena para el proyecto "De Taitas y de Mamas" obtuvo una nominación a la 14a Entrega Anual del Latin Grammy en la categoría Mejor Diseño de Empaque. El proyecto es una recopilación de música tradicional ecuatoriana y de sus representantes más legendarios, sin mostrar a ninguno de los músicos. La propuesta de Mena analizó sus casas, su vestimenta, sus texturas, su música y su vida para utilizarlos como referentes visuales en su diseño, y dar a la propuesta gráfica un aire del entorno cotidiano de estos músicos. (Salgado, 2013) 


\section{Diseño gráfico y patrimonio}

El Ecuador es muy rico en inspiración. Los pocos ejemplos que se muestran en este artículo dan una idea del potencial que tiene nuestro entorno y nuestro patrimonio cultural para generar ideas extraordinarias en el diseño gráfico, por lo que deberíamos seguir investigando para encontrar una identidad que nos caracterice. El diseño glocalizado, propuestas globales con aire local, son una opción que la han tomado muchos países y desde hace ya tiempo, podemos reconocer artículos mexicanos, chinos o egipcios sin dudar mucho al identificar su procedencia.

Sabemos que la mayoría de países latinoamericanos carecen de una cultura milenaria como la nuestra, así que podemos buscar a lo largo de 4000 años, desde que tenemos las primeras referencias en Valdivia, hasta nuestra forma de vida actual.
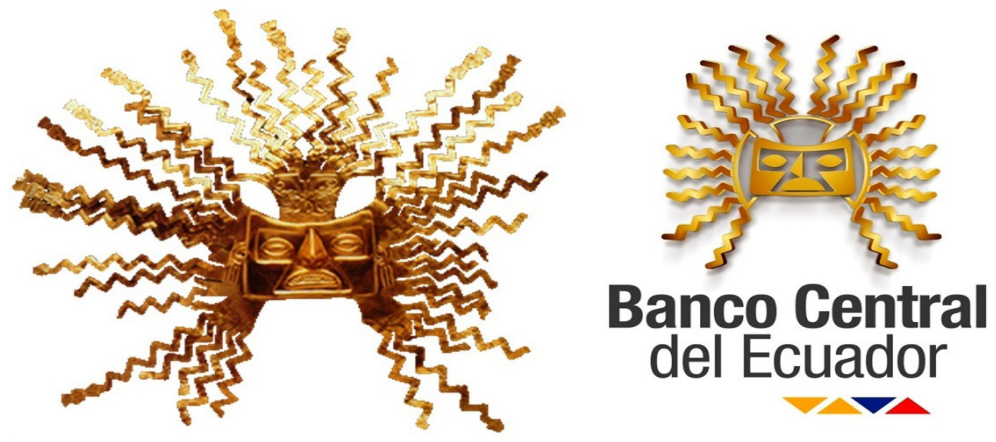
El peligro que corremos al inspirarnos en nuestro patrimonio y mal utilizarlo, es el de banalizarlo, ya ocurrió con nuestras venus y la artesanía en cerámica que copia lo precolombino, y que ahora se ve desgastado como referencia. También se han dado atentados contra nuestro patrimonio visual como el cambio, en el año 2013, del extraordinario Sol, la poderosa imagen visual que representaba al Banco Central, por una triste "actualización" que refleja un paupérrimo tratamiento gráfico.

Ese desgaste de lo precolombino o lo popular es fácilmente superado en cuanto miramos libros como El Arte Secreto del Ecuador Precolombino, de Daniel Klein e Iván Cruz Cevallos (Klein \& Cruz Cevallos, 2007), o Artesanías del Ecuador de Pablo Cuvi con la dirección artística de Paula Barragán (Cuvi, 1994). Es al mirar sus extraordinarias imágenes que volvemos a soñar con apropiarnos de esa exuberancia expresiva y riquísima de miles de formas, texturas, colores, usos, que hemos creado a lo largo de nuestra historia. 


\section{Referencias}

Cuvi, P. (1994). Artesanías del Ecuador (Primera Ed., p. 184). Quito: Dinediciones.

Gutiérrez, A. (n.d.). Peter Mussfeldt: El alemán que graficó el trópico. proyectoD.com. Retrieved from http://www.proyectod.com/finalizacion/maestros/3mussfelt.html

Klein, D., \& Cruz Cevallos, I. (2007). Ecuador El Arte Secreto del Ecuador Precolombino (Primera Ed., p. 360). Milán: 5 Continents.

Malo González, C. (2002, April). Cultura e Interculturalidad. Programa Andino de Derechos Humanos. Retrieved from http://www.uasb.edu.ec/padh/revista2/articulos/claudiomalo.htm

Mena, B. (2014). Más que un libro > Pachanga es un proyecto de vida. Belen Mena Design.

Moya Peralta, R. (1997). Logos: Logotipos e Isotipos Ecuatorianos (p. 108). Quito: Trama Ediciones.

Pérez Pimentel, R. (n.d.). Olga Fish. In Diccionario Biográfico Ecuador. Retrieved from

http://www.diccionariobiograficoecuador.com/tomos/tomo12/f2.htm

Salgado, E. (2010). Los Pájaros de Mussfeldt. Grafitat. Retrieved from http://www.grafitat.com/2010/02/22/los-pajaros-de-mussfeldt/

Salgado, E. (2013). De Taitas \& De Mamas en los Grammy Latinos. Grafitat. Retrieved from http://www.grafitat.com/2013/10/10/belenmena-en-los-grammy-latino/

Zúñiga, V. (2014). Proyectos seleccionados en Tipos Latinos 2014. Behance. Retrieved from https://www.behance.net/ gallery/16936417/Proyectos-Seleccionados-en-Tipos-Latinos-2014 


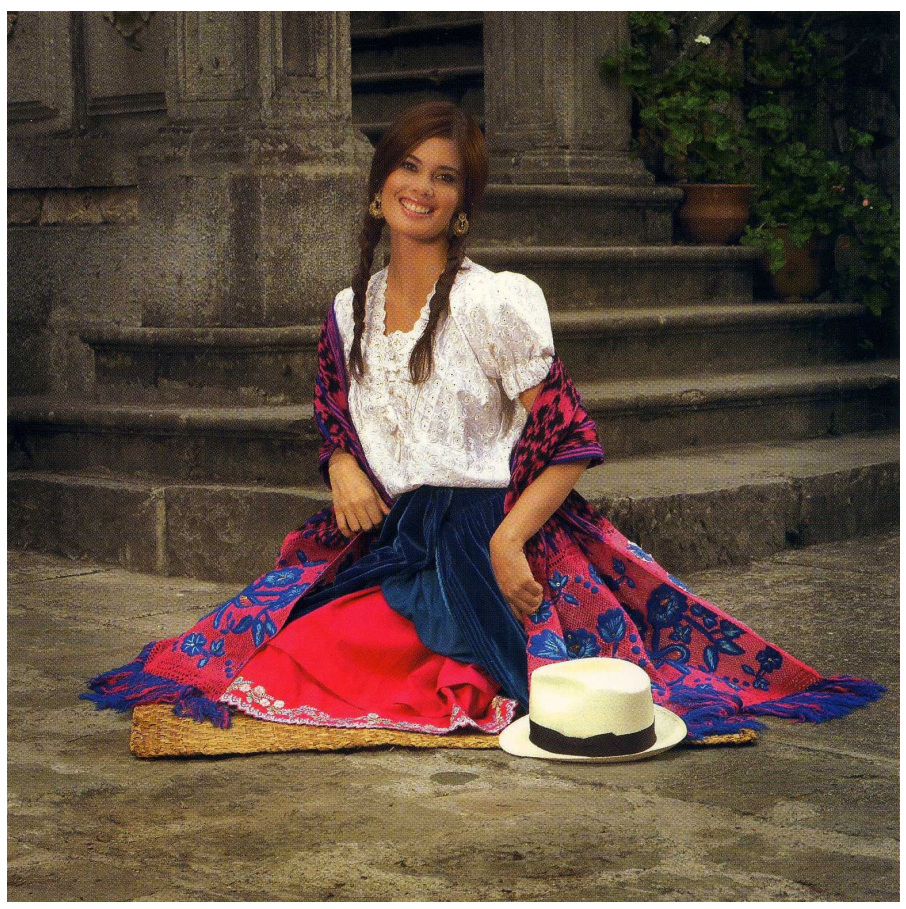

\title{
La Chola Cuencana
}

\author{
Arteaga Matute, Diego
}




\section{Resumen:}

En la actualidad un gran número de comunidades rurales de las provincias de Azuay y Cañar, entre sus actividades culturales eligen a las cholitas. Son mujeres que en todos los casos juegan un rol importante en sus celebraciones, sean éstas de parroquialización o de cantonización. Sin embargo, a pesar de que la chola se ha ido constituyendo en la figura emblemática del mestizaje biológico y cultural prácticamente no ha estado en los diferentes ámbitos de la vida comarcana. A diferencia de urbes como Lima o La Paz, prácticamente no hace acto de presencia en las diferentes facetas de sus vidas. En el caso de la chola cuencana ocurre algo parecido; en efecto, lo hace de manera breve en la literatura y es conocida a nivel local, nacional e internacional solamente por la canción titulada "Chola cuencana"; a esta situación hay que añadir que desde hace sólo unas décadas, con motivo de ciertas fiestas populares de la urbe y de sus parroquias rurales, va siendo elegida para presidirlas.

Palabras clave: Indio, negro, blanco, mestizaje biológico, mestizaje cultural, categoría, chola. 


\section{THE CHOLA CUENCANA}

\section{Abstract}

At present, a large number of rural communities in the provinces of Azuay and Cañar elect cholitas as part of their cultural activities. Cholitas are women who, in all cases, play an important role in these celebrations, whether they are the formation of parishes or cantons. However, despite the fact that the chola has become the emblematic figure of biological and cultural miscegenation, she practically has not been present in the different aspects of neighboring life. Unlike major cities like Lima or La Paz, she practically has no presence in the different facets of life. In the case of the Chola Cuencana, something very similar occurs; in fact, she is briefly mentioned in literature and is known at a local, national and international level solely for the song titled, "Chola Cuencana." It also must be noted that it's only been a few decades since the chola has been elected to preside over certain popular festivities in major cities and their rural parishes.

Keywords: Indian, black, white, biological miscegenation, cultural miscegenation, category, chola. 


\section{La ciudad de Cuenca}

La historia de la región en la cual hoy se levanta la moderna ciudad de Cuenca tiene vieja data con el establecimiento de sus primeros pobladores que llegaron hace unos 4.000 años. Estas gentes fueron pasando por diferentes etapas de evolución social, económica y tecnológica hasta el nivel conocido como jefatura representado por los cañaris, grupo que, tras una relativa resistencia, pasó a integrar el imperio inca, hacia 1460. La llegada de los europeos a la urbe inka de Tomebamba, por 1533, trajo consigo al negro, grupo racial que sumado al aborigen, así como a sus diferentes categorías de mestizaje biológico, constituyeron la población que le da origen en 1557.

Cuenca fue desde 1560 hasta la segunda mitad del siglo XVII un centro de actividad minera en la audiencia quiteña; luego su economía quedaría sustentada por la actividad agroganadera y artesana que la mantendrían como su segunda ciudad durante casi toda la época colonial, es decir hasta 1822, atrás únicamente de su capital, Quito. Ya a mediados del siglo XIX, empezaría a enrumbar sus destinos hacia otras actividades como la agricultura a gran escala, intentonas mineras, y a los textiles y, décadas más tarde, a la gran producción del sombrero de paja toquilla, que la introdujo en el mundo comercial internacional. En el siglo XX la caracterizarían algunas actividades industriales a nivel de Ecuador.

En sus inicios coloniales, fue organizada según el modelo del cuadriculado. En el centro de la traza, los 
núcleos de poder político y religioso, en los alrededores, las residencias de los blancos (sobre todo españoles, algunos portugueses e italianos); fuera de ella, los nativos. Pero en la práctica, reinaba en buena medida la convivencia racial que fue definiendo algunos barrios desde mediados del siglo XVII y que precisarían a su periferia. Estos lugares más tarde se convertirían en sectores de población mayoritariamente mestiza a finales del XVIII y que, ya en la república, se volverían en populares, condición que han mantenido hasta la actualidad, constituyendo parte de los límites geográficos de su denominado centro histórico.

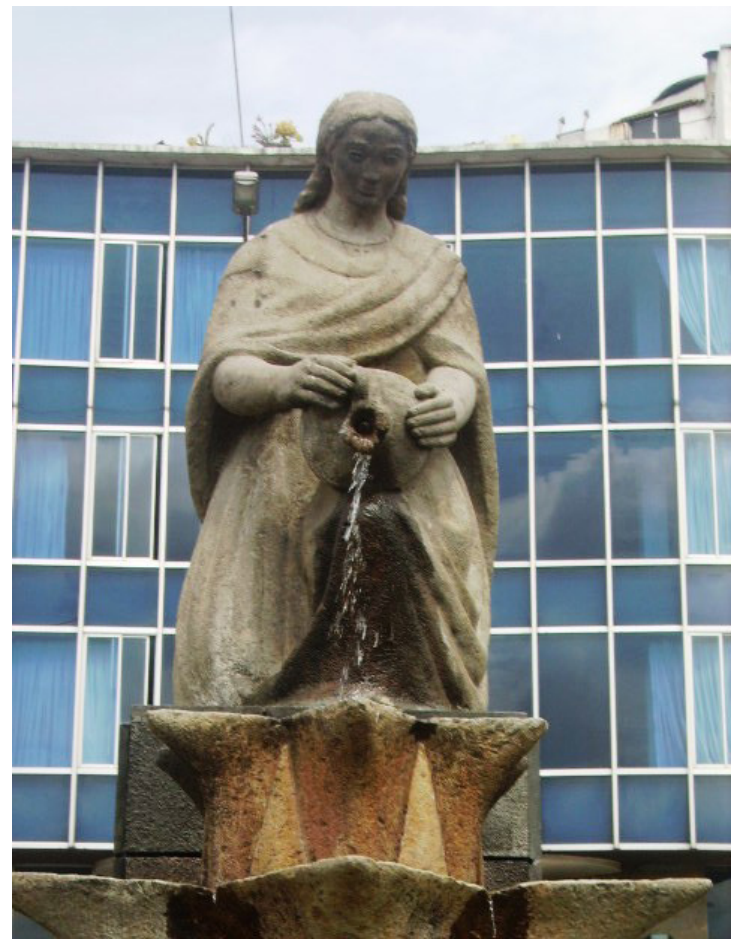




\section{El mestizaje biológico y cultural en América y en Cuenca: categorías}

A Cuenca se la ha etiquetado como una ciudad blancomestiza. En ella los componentes étnicos que le darían origen serían únicamente indios y blancos; sin embargo, la urbe cabe perfectamente dentro de aquellas andinas en donde se mantiene la expresión de "quien no tiene de inga tiene de mandinga", en clara alusión a la presencia de los tres grupos raciales: el negro (negroide) proveniente de África, el indio (mongoloide) del continente americano, y el blanco (caucasoide) de Europa, quienes se mezclarían biológicamente entre sí como parte de un proceso espectacular como no se había producido en ninguna otra parte del planeta, formando lo que Vasconcelos ha denominado la Raza Cósmica.

Concomitante con el mestizaje biológico se dio el cultural. El convivir diario de los diferentes grupos étnicos permearon sus usos y costumbres, unos más que otros, de esta manera fueron mezclándose elementos culinarios, tradiciones, idioma, religión, vestuario y muchos otros de la cultura material e inmaterial.

En el inicio del proceso biológico y cultural del mestizaje jugó un papel fundamental la presencia de la mujer aborigen. Desde las primeras incursiones españolas en tierras americanas estuvo al lado del descubridor y conquistador en calidad de, aunque como excepción, lengua (intérprete); también les acompañaba como concubina obtenida mediante botín de guerra, regalos de jefes aborígenes en señal de paz y amistad, o como "simples" asistentes, tal como lo hicieron las mujeres cañaris en 1547 (Cieza de León; 1553; folio ivj v). 
Las relaciones sexuales entre los españoles y las indias se dieron de forma regular o esporádica. El ibérico no tenía escrúpulos raciales o morales para establecer esos encuentros, pero sí expresaba su rechazo a ligarse a ellas mediante el matrimonio, excepto en algunos casos cuando la india pertenecía a la nobleza, con lo cual el blanco elevaba su situación en la nueva sociedad, como por ejemplo con lo sucedido en el siglo XVIII con la cacica de Deleg doña Rossa Quinde quien fuera esposa del español Romualdo Piedra (Arteaga; 2010; 2-5).

Pero al lado de estos aventureros estuvo también la mujer blanca y/o la negra, prueba de ello es la presencia en Cuenca de Mary López, quien resultó beneficiada con la inicial repartición de solares a los primeros pobladores de la urbe (LCC; I; 19), así como pocos años más tarde, la de negras y mulatas, personas con las cuales se iba afianzando en el área el proceso biológico y cultural de la mezcla de razas así como de sus diferentes categorías. Más escasa fue la pareja formada por un indio y una blanca. Sólo la Iglesia católica tuvo grandes reparos en este proceso pues con él "surge un problema moral de grandes proporciones en la medida en que el concubinato se institucionaliza y la familia se desarticula", según Malo González (1993; 215).

La sociedad colonial de las Indias occidentales fue organizada en forma asimétrica desde la época misma de la conquista en dos repúblicas: la república de españoles y la república de indios; este ordenamiento se correspondía con el que existía en la península: cristianos y moros de la época de la reconquista, continuación de aquella de cristianos y paganos, del medioevo europeo. 
Según el Diccionario de Autoridades -cuya primera edición data de 1726-, mestizo significa animal de padre y madre de razas diferentes (Caillavet \& Minchom; 1992; 129; nota 4); de esta manera se aplicó, el concepto en un primer momento, al resultado del cruce biológico entre animales, luego se lo hizo, y en este mismo sentido, al ser humano, concretamente al resultado de la mezcla del blanco con el indio. Pronto asomará en el escenario el negro -grupo racial que ya había estado en contacto con el español en calidad de esclavo incluso antes del descubrimiento de América de 1492-, quien también intervendría en este proceso biológico y cultural.

Pronto empezaron a darse cruces biológicos entre estos tres grupos raciales, cuyos resultados debían encasillarse según el porcentaje de "sangre blanca" que tuvieran, de esta manera asomaron las diferentes categorías del mestizaje, en donde también se aplicaría la asociación de ellas con animales, así tenemos: perros cholos, toros pardos, vacas mulatas. Esta práctica se dio en el virreinato peruano, por ejemplo en Lima, durante el siglo XVI (Flores Galindo; 1983; 340) costumbre que en Cuenca se extiende a lo largo del período colonial. Esta experiencia de asociación de personas de diferentes razas a la española con animales para la gente ibérica no resulta extraña, pues en su tierra hasta el comienzo del siglo $\mathrm{XVI}$ el criterio religioso y étnico les había hecho asociar a los judíos que residían en la península con herejes, perros y marranos, aunque hubo una contrapartida de los musulmanes: a los cristianos les mencionaban como "perros infieles". 
Muy pronto este criterio de pureza de sangre se aplicaría en las Indias occidentales; así el individuo resultante del cruce del blanco con indio, empezaría a ser conocido como mestizo, al del blanco con negro, mulato, etc. Pronto iniciaría, asimismo, a realizarse mezclas entre estos primeros cruces, que darían como resultado una gran variedad de individuos a los cuales había que encasillarles con su respectivo nombre, de esta manera empezaron a asomar distintas denominaciones para las categorías de mestizaje que, en la práctica, se convirtieron en indicadores sociales.

En el virreinato de México estas categorías llegaron a contabilizarse en unas 53, según Pitt-Rivers. Iban desde aquellas como mestizos (mezcla de blanco con india), sambo (mixtura de negro con india) pasando por otras como el mestindio, palabra que resulta de la contracción de las palabras mestizo e india, sus progenitores, hasta aquellos que, con seguridad, tenían que ver con criterios locales sobre este proceso, como el tresalbo (fusión de indio con mestiza) y el coyote, resultado de iguales progenitores, hasta otros que únicamente fueron anotados sin que se mencione los grupos que intervenían en el cruce: hablamos de lunajero, mesquimixto, rayado. En este sentido son interesantes los cuadros de castas que ofrecen pintores mexicanos del siglo XVIII (Katzew; 2007; 337-481).

En el virreinato peruano estas categorías se dieron en un número mucho menor pues apenas llegaron a 16 . Aquí también resulta interesante un cuadro de castas de la misma época en donde asoman las siguientes categorías: mulato, tercerón, cuarterón, quinterón, torna a blanco, sambo, sambohigo, tente en el aire, tira atrás, mestizo, 
cholo, tente en el aire, salta atrás, chino, rechino o criollo, torna atrás. En estas castas, cholo es el resultado del cruce de mestizo con india; además, el cholo mezclado con india da como resultado tente en el aire (Varallanos; 1962). ${ }^{1}$ De su parte, el mestizo Garcilaso de la Vega señalaba a comienzos del siglo XVII para su patria, Perú, la presencia de otras categorías como: cuatralbo y tresalbo.

En la Audiencia de Quito se tuvo algunas de estas castas, que no llegaban a la docena; en efecto, estuvieron presentes unas cuantas existentes tanto en México como en Perú, añadidas a otras propias de la región como los cambayiyos (Orive [1557] 1992; 62).

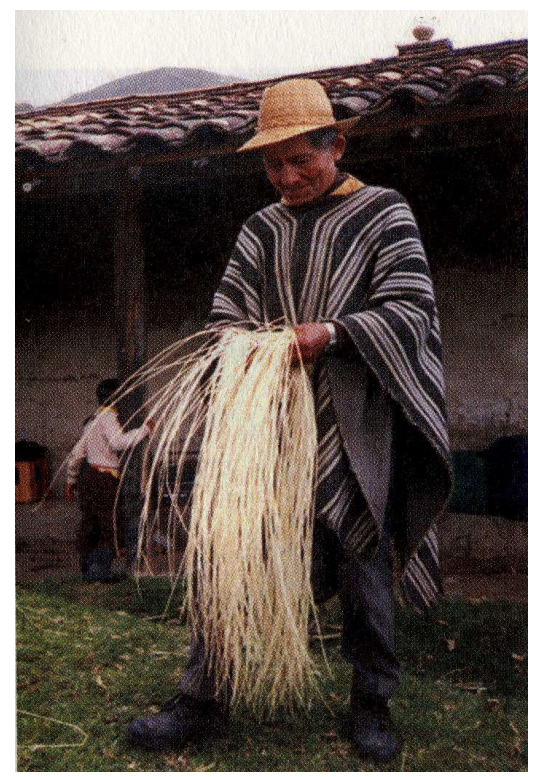

1 Este cuadro de castas no tiene paginación. En todo caso, está ubicado entre las páginas 132 y 133. 
De su lado, Cuenca no varió en gran medida en el número de estas últimas categorías: zambo, mulato, pardo, moreno, montañés, "cholos"; otras que también estuvieron presentes tales como: mestizo en hábito de indio, mestiza en hábito de india, mestizo en hábito de español, a más de una regional conocida como chazo.

\section{Lo cholo y la chola en Cuenca: la chola cuencana}

Tanto cholo como chola son términos que se presentan complejos para su análisis. Asoman en diferente medida en los documentos oficiales tanto inéditos como publicados. Si bien en estos se presenta con más frecuencia el varón que la mujer, esta vez haremos hincapié en ella.

\section{1.- Lo biológico}

A decir de la estudiosa Bouysse Cassagne -según el Diccionario de Ludovico Bertonio de 1612-, el término cholo/chola se originó en el idioma aymará, en la palabra chhullu, que señalaba al producto de la mezcla de animales de diferentes razas; por su lado, el cronista indio Felipe Guamán Poma de Ayala en su Nueva Corónica y buen Gobierno de 1613 indicaba que chola es aquella india que había roto el orden jerárquico de su grupo racial, viniendo a menos. ${ }^{2}$

En verdad, existen algunas otras "definiciones" de chola, que no muestran grandes variaciones en cuanto al significado. Ellas están relacionadas con mezcla de grupos raciales en donde siempre interviene el componente indio.

2 Más menciones respecto del origen de la palabra cholo se tienen en Varallanos (1962; 27; nota 16). 
Por su parte, el investigador Saignes anota que durante la colonia a la chola se la conocía como mestiza en ábito de india. La mestiza en ábito de india por esa época se consolidaba en la urbe cuencana, o más bien, en sus parroquias de indios, especialmente en San Sebastián, y algo menos en la de San Blas; también lo hace en su sector suburbano de Todos los Santos.

En la ciudad cuencana, a más de esta expresión presente desde el comienzo del siglo XVII, se tiene que aproximadamente un siglo más tarde cholita hacía alusión a las indias de servicio doméstico, según el visitador español Martínez de Arizala; un poco más al norte de la urbe, según Manuel Rendón en 1778 cholo "es [la persona] que acceden al mestizaje por la vía del desplazamiento de su indumentaria tradicional indígena, al incorporar prendas de origen español" (Fuentealba; 1992: 74).

\section{2.- Lo cultural: la indumentaria}

Paralelo al mestizaje biológico ocurrido en las Indias con la participación de indios, negros y blancos, se dio el proceso de mezcla cultural. En este sentido existen varios elementos tales como: comida, mobiliario, lenguaje, indumentaria, entre otros, que permiten conocer el mayor o menor grado de esta fusión.

La indumentaria de los pobladores del área cañari tanto de hombres como de mujeres ha sido "reducida" por los cronistas a camisetas y mantas. Según estos mismos escritores, los inkas, introdujeron en la zona otras prendas como la yacolla; además de esto, algunos indios usaban ojotas. Completaban los atuendos cañaris femeninos topo, brazaletes. En cambio, la indumentaria inkásica de 
la región puede ser mejor conocida mediante los extensos estudios que han desarrollado algunos etnohistoriadores como Murra, incluso es posible conocer sus diseños, por ejemplo a través de obras como la del ya mencionado, líneas arriba, Guamán Poma de Ayala.

En la Cuenca colonial, sobre todo en la segunda mitad de la centuria del dieciséis, hay mejores fuentes para estar al tanto respecto de las prendas indígenas, de esta manera van asomando moropacha, moroliclla, liquilla moro moro -prenda de carácter ritual femenina- (Arteaga; 2011; 1213) pasando por alçaanaco, patacusma hasta "camiseta de borrachera", asimismo prenda litúrgicas entre otras.

Según el Derecho español, los habitantes de sus colonias americanas debían usar diferentes tipos de trajes, de acuerdo a su grupo étnico. A estas disposiciones debían sumarse otras, locales, que iban caracterizando de alguna manera a unas cuantas urbes y pueblos. A manera de ejemplo señalamos que el Libro VII, Título Quinto de la Recopilación señalaba en la ley xxviij que: "Ninguna Negra libre, ó esclava, ni mulata, trayga oro, perlas, ni seda; pero si la negra, ó Mulata libre fuere casada con Español, pueda traer unos zarcillos de oro con perlas, y una gargantilla, y en la saya un rivete de terciopelo, y no puedan traer ni traigan mantos de burato, ni de otra tela, salvo mantellinas, que lleguen poco más debajo de la cintura, pena de que les quiten, y pierdan las joyas de oro, vestidos de seda, y manto que traxeren"; práctica que se confirmaba en algunas ciudades coloniales (Rosenblat; 1954; II; 156, nota 1). Nada se conoce de su acatamiento en Cuenca para el siglo XVI. En todo caso, durante el siguiente había un reconocimiento a una indumentaria únicamente para mestizas. 
Sin embargo, la vestimenta que llevaban los indios variaba entre ellos en gran medida y estaba en relación directa con su status social y económico. Los indios del común contaban con prendas que iban desde apenas una camisa y un calzón, pasando por individuos que poseían: camisa, manta, camiseta, calzón, hasta los que contaban además con: capote, "capotones", capa, y sombrero.

Por encima del indio del común estaban los dirigentes y entre quienes, asimismo, había notorias diferencias en cuanto vestimenta. Los había desde aquellos que apenas tenían: vestido, camiseta y sombrero; pasando por otros que contaban con: camiseta, calzón y capa; hasta aquellos que disponían solamente de ropa elaborada con telas importadas de Europa: turca, capa, capotillo, sayo, jubón, "çeregüelles", "ynpiriales", borceguí. Entre los mestizos, hay prendas de estilo europeo elaboradas con telas provenientes de Europa y América, e incluso cintillo de clara procedencia aborigen o con sombrero de alas, de estilo español, pero confeccionados con lana de vicuña.

A diferencia del varón colonial perteneciente al sector indio y mestizo, sus mujeres tenían, y por muchas razones, una mayor participación en el proceso de mestizaje biológico y cultural y en donde la indumentaria fue un elemento muy importante.

En el caso de las indias cañaris, resulta un tanto fácil anotar su ropa; sin embargo, durante la segunda mitad de la centuria del dieciséis se conoce un número mayor de sus prendas: alçaanaco, moropacha, moroliclla, patacusma, chumbe, mamachumbe, entre otras; así como complementos para el atuendo o partes de él tales como topo, y joyas como brazalete y zarcillo. 
Durante el siglo XVI la indumentaria de la mestiza se la conocía en Cuenca únicamente a través de las donaciones que recibían de mujeres blancas y/o indias, lo cual condicionaría el uso de estos estilos o de una mezcla de ellos. Para esas épocas sus ropas también dependerían del ambiente étnico y social donde la persona se criaba, haciéndola inclinar por el estilo europeo o, en otras ocasiones, por el indígena, o sino, por su mezcla.

Durante el XVII se aclara mucho más el ámbito del traje de la mestiza en Cuenca. Visten: basquiña de raso, manto de lana y seda, corpiño, vestido, saya, jubón, toca y chapín, prendas de estilo europeo, aunque representaban una mezcla de las destinadas a las clases baja y alta; algunas contaban con ropa labrada, es decir tejida, pero procedente de la región selvática de los quijos; otras con anaco, ligllas, "ropas", y, muy rara vez, faja o acsu. Con gargantillas, chaquiras" -estas últimas, piezas de auténtico estilo aborigen-, brazaletes de coral con perlas, y zarcillos, complementaban algunas mestizas su atuendo.

Especial mención merece la indumentaria de las mestizas en ábito de indias o cholas, pues si bien la presencia de estos personajes se dio en Cuenca desde el comienzo de la centuria del XVII, no es sino a partir de su último tercio que se dispone de mayor cantidad de información.

Usaban vestidos compuestos de faldellín y liglla, con una "franjita de hilo de oro"; también faldellín de "paño de la tierra"; pollera de bayeta -algunas con nueve vueltas de cintas amarillas, otras con tres guarniciones de sevillaneta, de la ancha, de oro; pollera de bayeta con vueltas de tafetán; polleras de cataluña -tela usada también para 
tejer alfombras- con tres guarniciones de sevillaneta de oro; pollera de estameña de la tierra con vueltas de cintas amarillas; liglla de bayeta de castilla, algunas con guarnición de sevillaneta de hilo de oro; liglla de lana de la tierra; liglla de chamelote; camisa de ruán; camisa de lienzo de la tierra, labradas con lana de diferentes colores; enagua de lienzo de la tierra; paño de cabeza de rengo con sus puntas grandes de Flandes; anaco de ormesí con su guarnición de sevillaneta de oro; piezas de "medio anaco" de castilla con cinco vueltas de sevillaneta de hilo de plata y una guarnición pequeña de punta de hilo de plata; pecho bordado con seda carmesí e hilo de oro y lentejuela; enagua de ruán; medias de seda.

Un análisis algo detenido de algunas de estas prendas nos va a permitir conocer de mejor manera su situación entre las cholas.

Los faldellines usados por estas cholas también lo fueron por blancas o por "señoras de distinción" según los españoles Juan y Ulloa (1748 I; 368), así como por indias. Mucho más amplio en la sociedad fue el uso de la pollera, prenda de estilo europeo -originada en el siglo $V$ antes de Cristo-, llevada por mujeres indias, blancas, y pardas. En Quito el ambiente para su uso fue diferente; en efecto, en 1647 la pragmática de su Majestad ordenaba entre otras cosas: "...que las mestizas no traigan guardainfantes, ni polleras debajo, ni puños con puntas de Flandes, so pena de pedimiento de lo que así trajeren en contravención a este auto..." (Peñaherrera de Costales; 1979; 31) lo cual, a su vez explicaría la razón por la cual en la época que visitaron esta ciudad Juan y Ulloa las blancas no usaban pollera (1748 I; 368). También la saya fue prenda usada por blancas a partir del siglo XVIII pero con casaca. Para 
el Quito de 1808 uno de los juegos de ropa de las mestizas fue descrito así:

...usan un gran miriñaque con saya de color llamativo hecha con franela inglesa, roja, rosada, amarilla, azul pálido, adornada de muchas cintas, encajes, flecos y lentejuelas, a modo de arabescos que casi abarcan media yarda de espacio, y llegan hasta el extremo de la blusa, debajo de la cual penden anchos encajes blancos cosidos a una prenda interior. (Steveson [1808] 1960; 228)

El anaco, otra prenda de tradición indígena, en el caso de las indias se complementaba con camisas que, a veces presentan, pecho (¿las actuales pecheras?) bordados, y de diferente tela que de la camisa; el anaco en el siglo XVII ya había adquirido en Cuenca una connotación peyorativa y de distintivo étnico: sólo al comienzo del XVIII se menciona el "medio anaco" que suponemos sería prenda de menor longitud que el de épocas anteriores. Peñaherrera de Costales señala en su estudio respecto de la mestiza quiteña (siglos XVI-XVIII) un asunto que puede empatar con el "medio anaco" cuencano: la mujer de esta categoría en Quito -dice-, aquella que pertenecía “....a una clase social intermedia en ocasiones se veía impedida a vestir a la usanza aborigen [...] Por eso -añadía- lucía anaco a media pierna, abierto al lado izquierdo, dejando libre paso a reluciente camisa-túnica blanca..." (1979; 31).

En la época republicana, en cambio, se conoce menor número de materiales con los que son elaboradas las polleras. No asoman en la documentación sea ésta inédita o publicada. En ellas prima el uso de la bayeta, que ha permanecido hasta la actualidad, fundamentalmente para gentes de los sectores rurales, ya que su uso ha 
quedado restringido a las mujeres aborígenes, aunque en la segunda mitad del sigo XIX, una que otra señora también la usaba en la zona urbana de Cuenca, tanto en las "interiores" como en las "exteriores": la primera quizá se trataba de un bolsicón $n^{3}$, prenda que se usaba por fuera de la pollera -y entre ellas el denominado centro-, tal como se mantiene hasta la actualidad en algunas comunidades indígenas de la provincia del Cañar, según la estudiosa Meisch (1980), y que son elaboradas con bayeta, bayetilla, o con "bayeta pellón".

Estas mestizas completaban el atuendo con enagua, prenda interior que estilaban, aunque de diferentes telas, también indias y blancas. Asimismo, es digno de destacar en estas mestizas el uso del paño de cabeza -la denominada ñañaca, en Bolivia- ropa que también la llevaban las indias de la nobleza y que contrastarían con los ceñidores de cabeza, de las blancas. En este punto es importante señalar que en un cuadro de fines del siglo XIX atribuido al artista ecuatoriano Manosalvas, el mismo que habría sido pintado durante su estancia en Cuenca y que retratara a una mujer de su región, muestra el paño de cabeza, elemento que, como se ve, pervivía como signo de distinción femenino aunque, en verdad, en este caso no se conoce el status social y económico, o el grupo étnico de la representada.

Las prendas de estilo indígena de estas mestizas no pertenecian a ninguna etnia en particular, sea liquida (más tarde denominadas liglla), anaco y, más raramente, faja; tampoco las joyas que usaban son de exclusiva procedencia india, sino más bien una mezcla de estilos. 3 A decir de Sosa Cevallos \& Durán Camacho (1996), en Quito el término bolsicona estaba dado "por los bolsillos que llevaba [la mujer] en su falda". 
Como excepción a esto quizá puede señalarse el uso de los aretes de media luna conocidos hasta la actualidad como candongas, y los "cintillos. No deja de causar extrañeza entre estas piezas la ausencia del topo que sujeta la liglla. ${ }^{4}$

En verdad, no debe llamar la atención el hecho de que en el siglo XVIII, una época de proliferación de mestizas en Cuenca y sus alrededores, sean quienes, por un lado, hayan mantenido algunas prendas de tradición aborigen que, dicho sea de paso, eran las de más frecuente uso entre las indias $y$, por otro, que prácticamente sean quienes empiecen a poner de moda la pollera, aunque algo parecido ocurría por esa época en La Paz (Barragán; 1992).

En términos generales, durante la época colonial las leyes señalaban, entre otros asuntos, el tipo de indumentaria y complementos para cada grupo étnico, así como para las diferentes categorías de mestizaje. En este último punto quizá el ejemplo más evidente son los distintos "cuadros del mestizaje" de la sociedad mejicana ofrecidos por Rosenblat (1954; 168-173). A parte de ello, obviamente el tipo de vestimenta también depende de la condición social y económica del individuo. A lo largo de la época republicana, en cambio, las leyes ecuatorianas señalaban únicamente la categoría de ciudadanos, pero en la práctica continuaban las diferencias entre blancos e indios -también se legisló de manera particular para estos últimos-, así como la existencia de algunas categorías de mestizaje "flotando en el ambiente" y que, de vez en cuando, asomaban en los documentos públicos; pero continuaban los criterios respecto de que la vestimenta era 4 Respecto de las joyas de estilo prehispánico de la región cañari prehispánica, presentes en la temprana Colonia puede consultarse Arteaga; 2009; 2-5. 
un buen indicador de la condición social y económica de la persona.

Con los datos disponibles no es posible, aún, señalar los cambios que ha tenido la indumentaria indígena en Cuenca y sus región, mucho menos de la que ha usado la mujer mestiza, y la chola en particular, pues a manera de ejemplo, la saya pasará a ser identificada, con el paso del tiempo, con el bolsicón (Arteaga; 1999; 100); la blusa tendrá sus variedades, -incluso en el cantón Cañar del siglo XIX están presentes de forma simultánea estas dos piezas- a veces, incluso, se la identificará con la polca; en la pollera, los variados números de vueltas de cintas de variados colores y telas desaparecen; asimismo se pierden en la indumentaria local y regional los anacos, mientras que en algunas zonas rurales de la provincia del Cañar únicamente perdura la liglla...

Hasta hace unas cuatro décadas, la indumentaria de la chola cuencana es señalada así: "dos polleras: la de adentro, bellamente bordada con flores y guirnaldas de colores, y sobre ésta, otra de un solo color, festoneada; la blusa lleva también adornados de alforzas, bordados y lentejuelas", a más de paño de ikat y sombrero de paja toquilla (Martínez Borrero \& Sojos de Peña; 1982; 19), amén de las candongas. Algo en lo que no se ha hecho hincapié por parte de los estudiosos respecto de la indumentaria de la chola es el uso de medias de seda y zapatos de charol; estos últimos, hasta hace unas décadas, se compraba en el prestigioso almacén de calzado "Corona". 


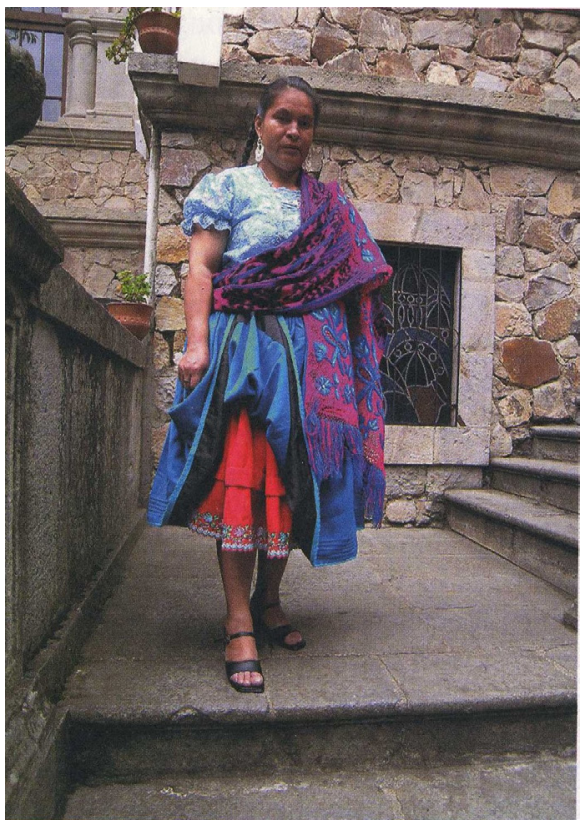

\section{Cholo y chola en la sociedad local: la chola, una figura emblemática}

Como se ha señalado líneas arriba, es el varón quien más asoma en la documentación. Así, se sabe que a comienzos del siglo XIX, El Eco del Asuay, en un Remitido de fecha domingo 24 de febrero de 1828 mostraba el siguiente texto:

Sr. editor: dignese V. satisfacer á estas pregunticas: ¿si habrá arbitrio para quitar algunas libras de los quintales de paciencia que tienen ciertos Alcaldes en escuchar demandas sobre insultos y dicterios? ¿Si merecerán una seria atención las ridículas expresiones de pu.... Cho...., y otras de este jaez? ¿Qué es lo 
que prescribe la ley en estos casos? ¿Viven aun entre nosotros algunos decendientes de D. Quijote? ¿Qué pretenden con semejante conducta estos bravos republicanos?

Un Cholo

Unos años antes, se informaba respecto de un hombre que fue reclutado para las huestes independentistas en los siguientes términos:

Allí [en El Ejido] las tropas del General Santa Cruz reclutaron al cholo Alvarado, que después llegó a ser General del Perú. La hermosa planicie, jardín y huerto en perpetua primavera, ha llamado siempre la atención de los viajeros ilustres que la han visitado, El Ejido se llamó, en los remotos tiempos coloniales, la Nueva Jamaica, con unos 10.000 habitantes." (Borrero; [1922] 1972; 537).

Mientras tanto que en el Perú de la segunda década del siglo XIX hubo los denominados "Cholos Insurgentes". Estas denominaciones las hubo en Charcas y Oruro (Cahill; 1994; 334; nota 34).

En lo gráfico, es menos lo que se puede decir del cholo o de la chola. Soruco Sologuren, señala que, fechada en torno al año 1900, existe una foto de un grupo de personas cuencanas titulada "La creencia y la solemnidad", en donde se observan "por los sombreros de paja toquilla y las mantas, a indígenas y cholos urbanos" (¿respectivamente?) (2003; 37): en verdad, señalar a una persona como cholo sólo porque lleva una manta, es algo simple. 
Para el caso del cholo, a mediados del siglo XIX se lo representaba a uno señalado como "Cholo de Cuenca en la procesión de Viernes Santo" (AA.VV; 2005; 271). Es un individuo vestido muy elegantemente. Como digno de destacar es el uso de los zapatos. Hay que tener presente, para efectos de comparación, los dos cholos presentados en esta misma obra: uno descalzo, otro usa zapatos, aunque ambos lucen asimismo elegantes (AA.VV; 2005; 320).

A lo largo de la historia local colonial y republicana, la mención de chola en Cuenca también es bastante escasa. El naturalista Enrique Festa, testigo de las acciones militares que se dieron en 1896 al producirse el "paso" del periodo progresista al que dio origen la revolución liberal, durante el tránsito del siglo XIX al XX señalaba "que las cholas cuencanas habían declarado que en caso de derrota masacrarían a los partidarios de [Eloy] Alfaro que estaban encerrados en las cárceles" ([1896], 1983, 141142);

De hecho, el término chola ha variado respecto de su significado de una ciudad a otra y aun dentro de éstas, con el paso del tiempo. Así, en Cuenca al comienzo del siglo XX se manifestaba que a la india que llegaba a la urbe, a veces, ésta le ofrecía mejores rumbos que a la mayoría de sus congéneres: "Amante de un hacendado o de un empleado de la ciudad [quien] comienza por modificar el vestido: zapato chillón, pollera de bayeta fina, polca de seda y paño de Gualaceo y, por fin una modesta pulpería que, casi siempre, la india transformada en chola suele manejar con economía y tino" (Aguilar Vázquez; $1940 ; 143)$. En todo caso, no es posible conocer las características fenotípicas de la chola. 
Hoy en día el término cholo suele ser utilizado en el cantón Cañar -provincia homónima-, para indicar que un indio ha dado el "primer paso" hacia el mestizaje cultural (Fock; 1980; 413); en otros casos, incluso ha sido peyorativo; otros, expresan muestras de un trato familiar, especialmente cuando está dirigido a niños y niñas y en diminutivo: cholito o cholita, respectivamente.

En la ciudad de Cuenca la chola asoma aisladamente. Es así que esta categoría no conformaba agrupaciones que identificaran a sectores de la urbe tal como lo hicieron las choladas de algunos barrios limeños (Cahill; 1994; 337; nota 35); tampoco constituyó un grupo o personas que se distinguieran demasiado en los estratos bajos de la sociedad local, a diferencia de otros sitios americanos, como lo ocurrido en el pueblo de Pory de Santa Ana, cercano a Cusco, en donde los cholos fueron considerados como indios "forasteros" sujetos a tributo, según Cahill (1994; 337; nota 34).

Tampoco existen criterios que señalen algunas características de la personalidad del cholo o de la chola como sí los hay, por ejemplo, de la cholita paceña boliviana, vista como una mujer trabajadora, que cuida de sus hijos, mientras el cholo, su esposo, es borracho, pendenciero, despreocupado de sus obligaciones para con su hogar. Algo más amplio en este sentido es la opinión de Varallanos (1962) para Perú. En cambio, en la cercana villa decimonónica de Azogues, la chola fue considerada como una mujer bravucona, aunque no se mencionaba con claridad su condición étnica ni social (Arteaga; en prensa). La única excepción en Cuenca a esta situación puede ser la existencia de la famosa chola 
Cusinga $^{5}$-Manuelita Quezada-, mujer capaz de provocar grandes pasiones al médico Senierges, miembro de la primera Misión Geodésica Francesa que llegara a Cuenca por 1735 , provocando incluso la muerte de éste.

En todo caso, la chola a lo largo de la historia cuencana de la segunda mitad del siglo $X X$, se fue convirtiendo en su figura emblemática, luego de que el Centro Agrícola Cantonal, procediera a elegirlas para presidir las fiestas de aniversario de la fundación española de la urbe. De otro lado, no sabemos en qué medida fue considerada la tapada ${ }^{6}$ cuencana, de mediados del siglo dieciocho como representativa de las mujeres locales. Hoy en día, a más de ser el icono de la identidad de Cuenca, se la elige para las festividades de abril provocando, incluso, disputas entre las juntas parroquiales y el municipio local, pues cada uno considera que es "dueño de la verdadera chola cuencana"; además, puede ser considerada como figura de cuerpos profesionales a través de sus canciones, como la "Cholita doctora", entre los médicos.

Hoy en día la chola, por un lado, es vista y, por otro, se considera a sí misma como una mujer que se siente orgullosa de su piel blanca, pero al mismo tiempo, de su indumentaria, de procedencia indígena, en su mayor parte.

5 En Cuenca existen referencias a varias mujeres apodadas cucingas, cuyo significado podría ser alegre o alegrona; de hecho, en la urbe colonial existió una mujer llamada María Cushigo "aleas fandango" (Arteaga; 2003; 51).

6 Según Castañeda León $(1981 ; 57)$ "Un traje que sin lugar a dudas puede considerarse como manifestación típicamente limeña de la etapa colonial es la tapada (...) .apareció a raíz de la fundación de Lima (y duró) hasta comienzos de la segunda mitad del siglo XIX", convirtiéndose en su figura emblemática. 


\section{Bibliografía}

\section{Fuentes Primarias:}

Cieça de León, Pedro, 1553, Parte primera de la Chronica del Perú. Que tracta la demarcación de fus prouincias: la defcripción dellas. Las fundaciones de las nueuas ciudades. Los ritos y coftumbres de los indios. Y otras cofas eftrañas dignas de fer fabidas, 135 páginas.

El Eco del Asuay, (1828), 1994, Colección de Periódicos Ecuatorianos III, Publicaciones del Banco Central del Ecuador, 167 páginas.

Festa, Enrique, [1896], 1983, "Cuenca, escenario de una de las Guerras Civiles", Compilación de Crónicas, Relatos y Descripciones de Cuenca y su Provincia, Tercera Parte, Banco Central del Ecuador, Cuenca- Ecuador, pp.125-143.

Majó Framis, Ricardo, (1739) 1983, “Cuenca de Indias”, Compilación de Crónicas, Relatos y Descripciones de Cuenca, Segunda Parte, Banco Central del Ecuador, pp. 131-135.

Guamán Poma de Ayala, Felipe, [1613)] 1980, La Nueva Corónica y Buen Gobierno, John V. Murra y Rolena Adorno, Eds., Siglo $\mathrm{XXI}, 3$ volúmenes.

Juan Jorge \& Antonio de Ulloa, 1748, Relación Histórica del Viage a la América Meridional, Primera Parte, Tomo Primero, Madrid, 404 páginas.

Libro Primero de Cabildos de Cuenca (1557-1563), (LCC I), 1938, Archivo Histórico Municipal de Quito, Versión paleográfica de J. Garcés. 
Recio, Bernardo, [1776] 1947, Compendiosa Relación de la cristiandad de Quito, Consejo Superior de Investigaciones Científicas, Madrid.

Recopilación de leyes de los Reynos de las indias, 1774, Tercera edición, Madrid.

Solórzano y Pereira, Juan de, 1736, Política Indiana, Tercera Impresión por Mateo Sacristán, 2 volúmenes.

Stevenson, W. B, (1808), 1960, El Ecuador visto por los extranjeros (Viajeros de los siglos XVIII y XIX), Editorial J. M. Cajica Jr., S. A. Puebla.- México, pp. 193-237.

\section{Estudios:}

Aguilar Vázquez, Carlos, 1940, "Páginas de Higiene", Anales de la Universidad de Cuenca, pp. 125-172.

Arteaga, Diego, 1999, "Tras las huellas de la Chola cuencana (Siglos XVI-XVII), Estudios, Crónicas y relatos de Nuestra Tierra, II, Casa de la Cultura Ecuatoriana, Núcleo del Azuay, pp. 93-102.

Arteaga, Diego, 2001, "La Cuenca Negra”, COLOQUIO. Revista de la Universidad del Azuay, Año 2, Número 9, abril-junio, pp. 2-3.

Arteaga, Diego, 2003, "Sobre el origen de la chola cuencana", $A R C A, 1$, Revista de Cultura, Casa de la Cultura Ecuatoriana, Núcleo del Azuay, pp. 56-59.

Arteaga, Diego, 2009, “Joyas prehispánicas en la temprana región cuencana”, COLOQUIO. Revista de la Universidad del Azuay, Año 11, Número 40, pp. 2-5.

Arteaga, Diego, 2010, "La cacica doña Rossa Quinde y sus implicaciones socioétnicas en el Deleg del siglo XVIII", COLOQUIO. Revista de la Universidad del Azuay, Año 12, Número 45, pp. 2-5. 
Arteaga, Diego, 2011, "Sobre algunos elementos de la religión ancestral en la región cañari", Patrimonio Cultural Inmaterial, Nro. 2, Año 1, pp. 12-13.

Arteaga, Diego, en prensa, "De cholas, zambos y mulatos en Azogues en el siglo XIX".

AA.VV, 2005, Imágenes de identidad. Acuarelas quiteñas del siglo XIX, Biblioteca Básica de Quito, FONSAL 6, Quito, 563 páginas.

Barragán, Rossana, 1992, "Entre polleras, ñañacas y lliqllas. Los mestizos y las cholas en la conformación de la Tercera República", Henrique Urbano (comp.), Tradición y modernidad en los Andes, Cusco, Centro Bartolomé de las Casas, pp. 4673.

Borrero, Alfonso María, 1972 (1922), Cuenca en Pichincha, Tomo II, Casa de la Cultura Ecuatoriana, Núcleo del Azuay, 571 páginas.

Bouysse Cassagne, Thérèse; 1991, "Être métis ou ne pas être: les symptômes d'un mal identitaire dans les Andes des XVle et XVIle siècle", Cahiers des Amériques latine, pp. 7-24.

Cahill, David, 1994, "Colour by numbers: Racial and Ethnic categories in the Viceroyalty of Peru, 1532-1824", J. Amer. Stud., Cambridge University, 26, pp. 325-346.

Caillavet, Chantal \& Martin, Minchom 1992, "Le Métis imaginaire: idéaux classificatoires et stratégies socio-raciales en Amérique latine, L'Homme, 122-124, avr-déc. XXXII (2-3-4), pp. 115-132.

Carrasco V., Manuel, 1997, "Teoría y memoria del chaso azuayo", Cabeza de Gallo, Enero, Año 4, Número 6, pp. 59-64.

Castañeda León, Laura, 1981, Vestido tradicional del Perú, Museo Nacional de la Cultura Peruana. 
Encalada Vásquez, Oswaldo, 2007, Naturaleza, lengua y cultura, Universidad del Azuay / Corporación Editora Nacional, 260 páginas.

Fock, Niels, 1980, "Ethnicity and Alternative Identification: an example from Cañar", Cultural Transformations and Ethnicity in Modern Ecuador, Ed. By Norman E. Whiten, Jr., University Illinois Press, Urbana, pp. 403-419.

Fuentealba, Gerardo, 1992, "Forasteros, comunidades indígenas, Estado y grupos de poder en la Audiencia de Quito, siglo XVIII", Revista Ecuatoriana de Historia Económica, Año IV- No. 8 Segundo - Semestre, Banco Central del Ecuador, pp. 59-98.

Katzew, Ilona, 2007, "Estrellas en el Mar de la Iglesia: los indios en la pintura novohispana del siglo XVIII", Revelaciones. Las artes en América Latina 1492-1820, Fondo de Cultura Económica / Antiguo Colegio de San Ildefonso/Philadelphia Museum of Art/ Los Ángeles County Museum of Art, pp. 337-481.

Malo González, Claudio, 1993, "El mestizaje y sus problemas", 500 años. Historia, Actualidad y Perspectiva, Seminario Agustín Cueva Dávila, Universidad de Cuenca, CONUEP, ILDIS, Cuenca.

Martínez Borrero, Juan \& Sojos de Peña, Diana, 1982, El Traje Popular Ecuatoriano, Centro Interamericano de Artesanías y Artes Populares, Cuenca, Ecuador, 36 páginas.

Meisch, Lynn Ann, 1980, "The cañari People. Their Costume and Weaving”, El Palacio, Vol. 86, No. 3, Fall, pp.15-26.

Mörner, Magnus, 1969, La mezcla de razas en la historia de América Latina, Editorial Paidos, Buenos Aires, 163 páginas.

Peñaherrera de Costales, Piedad, 1979, "La mestiza Quiteña", Espejo, Revista Trimestral de CEPE, Año I, N 1, pp. 29-34. 
Pitt-Rivers, Julian, 1992, "La culture métisse: dynamique du Estatut ethnique, L'Homme 122-124, avr-déc. XXXII (2-3-4), pp. 134148.

Rosenblat, Ángel, 1954, El mestizaje y las castas coloniales I, Editorial Nova, Buenos Aires, 191 páginas.

Rubio Orive, Gonzalo, 1965, Aspectos Indígenas, Editorial de la Casa de la Cultura del Ecuador, Quito, 250 páginas.

Ruizgómez Gómez, Carmen, et. al. 2000, Documentos sobre la visita a Cuenca (Ecuador) del Oidor Pedro Martínez de Arizala y su Proyecto de Reforma (1726-1748), Documentos Tavera 12, Fundación Histórica Tavera, 254 páginas.

Saignes, Thierry, 1990, “¿Es posible una 'historia chola' del Perú? (Acerca del Nacimiento de una Utopía de Manuel Burga)", Allpanchis, XXII, 35-36, II, pp. 635-357.

Soruco Sologuren, Ximena, 2003, “Una 'biografía' urbana de linaje colonial", Arca. Revista de Cultura, Casa de la Cultura Ecuatoriana, Núcleo del Azuay, pp. 30-39.

Sosa Cevallos, Ximena \& Durán Camacho, Cecilia, 1996, "Familia, ciudad y vida cotidiana en el siglo XIX", Nueva Historia del Ecuador, Época Republicana II, Volumen 8, Corporación Editora Nacional, pp. 157-191.

Varallanos, José, 1962, El cholo y el Perú. Introducción al estudio sociológico de un hombre y un pueblo mestizos y su destino cultural, Imprenta López, Buenos Aires, 287 páginas. 